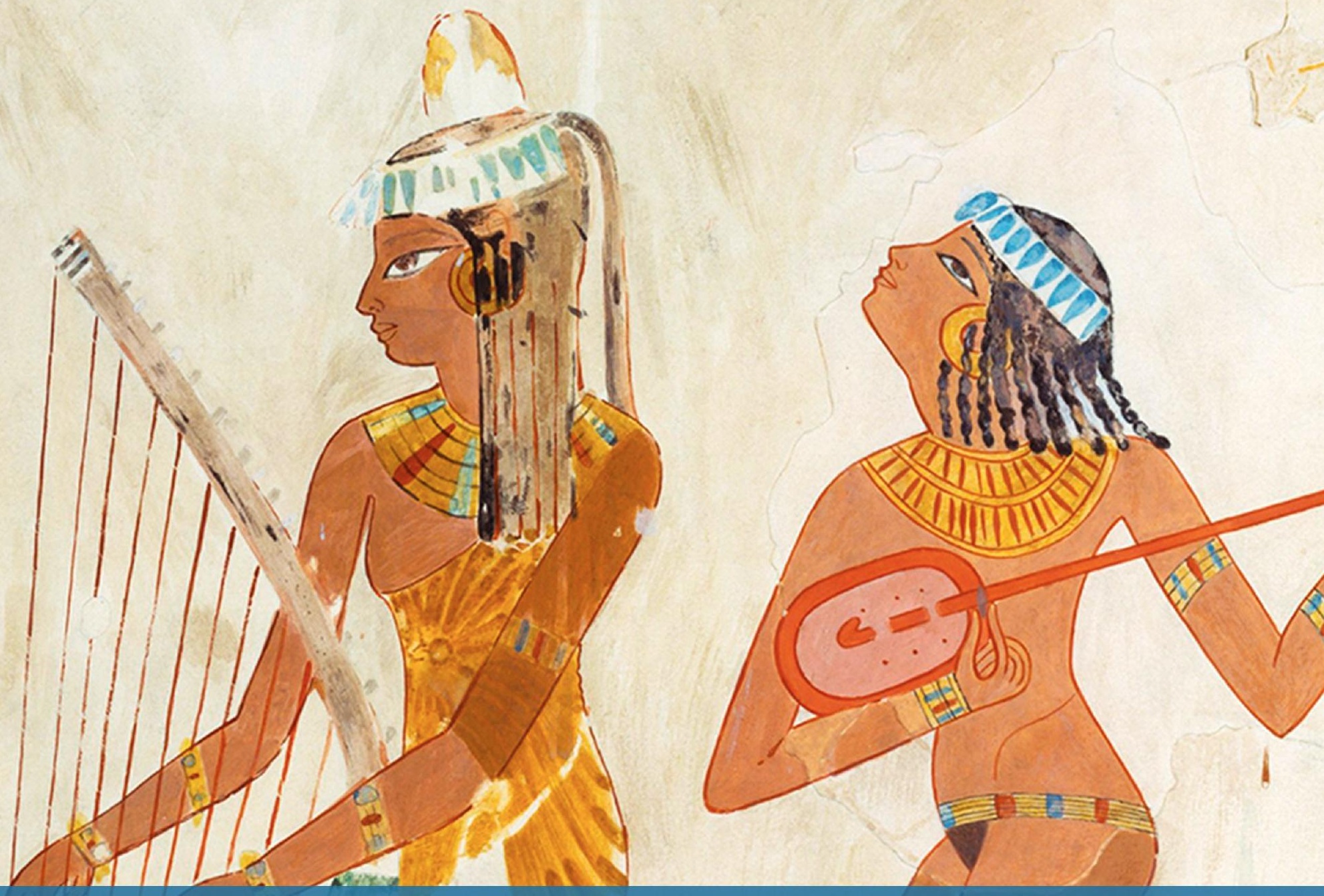

Revista digital de ciencia y Didáctica de la Historia

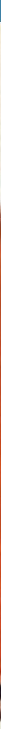




\section{Panta Rei \\ Revista Digital de Ciencia \\ y Didáctica de la Historia}

\section{9}

Revista anual

Fecha de inicio: 1995

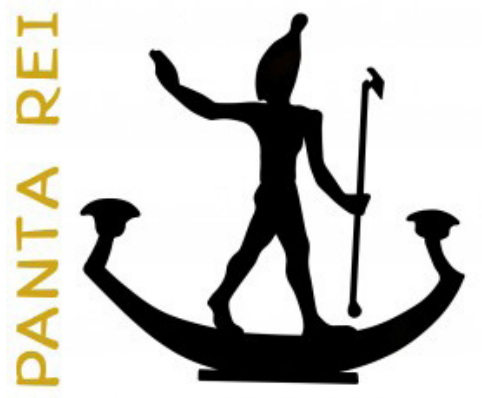

Revista Panta Rei. pantarei@um.es

Edita:

Centro de Estudios del Próximo Oriente y la

Antigüedad Tardía - CEPOAT

Edificio Universitario Saavedra Fajardo.

Universidad de Murcia

C/ Actor Isidoro Máiquez, 9

30007 - MURCIA - ESPAÑA

Teléfono: (+34) 868883890

cepoat@um.es

Web: www.um.es/cepoat/pantarei

Edición 2019

ISSNe: 2386-8864

Responsable de la presente edición: Consejo Editorial Panta Rei.

UNIVERSIDAD DE MURCIA centro de estudios del próximo oriente y la antigüedad tardía

En Portada: Fragmento de pintura de la tumba de Djeserkareseneb (TT38), Tebas. (fotografía del Metropolitan Museum).

Responsables de los textos: Sus autores.

ISSN: 1136-2464

Depósito legal: MU-966-1995 


\section{CONSEJO DE REDACCIÓN}

\section{Coordinador editorial}

Egea Vivancos, Alejandro

[Didáctica de las Ciencias Sociales, UMU]

\section{Editores}

Jiménez Vialás, Helena

[UMU]

López Muñoz, Dámaris

[UJA]

Meseguer Gil, Antonio José

[CEPOAT, UNED]

Sáez Giménez, David Omar

[CEPOAT, UMU]

Sánchez Mondéjar, Celso Miguel

[Patrimonio Inteligente]

\section{Secretaria}

Arias Ferrer, Laura

[Didáctica de las Ciencias Sociales, UMU]

\section{Responsable informático}

Martínez García, José Javier

[CEPOAT, UMU]

\section{Traducción y corrección lingüística}

Martínez Martínez, Cristina

[Sociedad Española de Lenguas Modernas]

Albaladejo Albaladejo, Sara

[ISEN, UMU]

\section{CONSEJO ASESOR}

Adroher Auroux, Andrés María [Arqueología, Universidad de Granada]

Albero Muñoz, M. ${ }^{a}$ del Mar [Historia del Arte, Universidad de Murcia]

Alia Miranda, Francisco [Historia Contemporánea, UCLM]

Arciniega García, Luis [Historia del Arte, Universidad de Valencia]

Barrio Barrio, Juan Antonio [Historia Medieval, Universidad de Alicante]

Castellano i Solé, Núria [Egiptología, Schola Didàctica Activa S.L.]
Chapman, Arthur [History Education, University College of London, Reino Unido]

Cid López, Rosa María [Historia Antigua, Universidad de Oviedo]

Cobacho López, Ángel [Derecho, Universidad de Murcia]

Cuenca López, José María [Didáctica de las Ciencias Sociales, Universidad de Huelva]

Egea Bruno, Pedro M. ${ }^{a}$ [Historia Contemporánea, Universidad de Murcia]

Feijoo Martínez, Santiago [Arqueología, Consorcio Ciudad Monumental de Mérida]

García Atienzar, Gabriel [Prehistoria, Universidad de Alicante]

Ginestí Rosell, Anna [Filología Clásica, Katholische Universität Eichstätt-Ingolstadt]

González Monfort, Neus [Didáctica de las Ciencias Sociales, Universidad Autónoma de Barcelona]

González Soutelo, Silvia [Arqueología, Universidad de Vigo]

Haber Uriarte, María [Prehistoria, Universidad de Murcia]

Hernández de la Fuente, David [Historia Antigua, Universidad Complutense]

Hutson, Scott R. [Anthropology, University of Kentucky, EE UU]

Igual Luis, David [Historia Medieval, UCLM]

Irigoyen López, Antonio [Historia Moderna, Universidad de Murcia]

Jover Maestre, Francisco Javier [Prehistoria, Universidad de Alicante]

Mahony, Simon [Digital Humanities, University College of London, Reino Unido]

Marsilla de Pascual, Francisco Reyes [Técnicas historiográficas, Universidad de Murcia]

Martínez-Burgos García, Palma [Historia del Arte, UCLM]

Mathis, Christian [Didaktik der Geschichte, PH Zürich]

Miralles Maldonado, José Carlos [Filología Clásica, Universidad de Murcia]

Molina Gómez, José Antonio [Historia Antigua, Universidad de Murcia]

Mónica Ghirardi [Historia Moderna, Universidad Nacional de Córdoba, Argentina]

Navarro Espinach, Germán [Historia Medieval, Universidad de Zaragoza]

Noguera Celdrán, José Miguel [Arqueología, Universidad de Murcia]

Ortiz Heras, Manuel [Historia Contemporánea, UCLM]

Panzram, Sabine [Historia Antigua, Universität Hamburg]

Pérez Molina, Miguel Emilio [Filología Clásica, Universidad de Murcia]

Prados Martínez, Fernando [Arqueología, Universidad de Alicante]

Sánchez Ibáñez, Raquel [Didáctica de las Ciencias Sociales, Universidad de Murcia]

Sancho Gómez, Miguel Pablo [Educación, UCAM]

Victoria Moreno, Diego [Historia Contemporánea, UNED]

Vilar García, María José [Historia Contemporánea, Universidad de Murcia]

Vivas Sainz, Inmaculada [Historia del Arte, UNED]

Zamora López, José Ángel [Próximo Oriente Antiguo, CCHS-CSIC] 



\section{Índice}

\section{Artículos}

La imagen de la Prehistoria en el cine y los géneros del cine prehistórico. Un mundo de hombres mono, bikinis y dinosaurios.

Alberto Lombo Montañés.

Trabajo y roles de género durante la Prehistoria. Un estudio sobre su percepción en el alumnado de Historia.

María Pastor Quiles y Daniel Mateo Corredor.

Memoria cultural en el Egipto Faraónico. Algunas reflexiones sobre su origen, función y pervivencia histórica.

Antonio Pérez Largacha.

La representación de la danza dentro de las escenas de banquete de las tumbas tebanas privadas de la XVIII dinastía egipcia.

Miriam Bueno Guardia.

La "Sala del Fresco" de Micenas. Revisión de las interpretaciones del programa iconográfico y nueva lectura en relación a los espacios.

Pelayo Huerta Segovia.

Las advertencias de Quilón y Solón sobre la tiranía de Pisístrato.

Unai Iriarte.

La Virgen de la Leche. Arquetipo de mujer y madre en la pintura del Renacimiento español.

Patricia Castiñeyra Fernández

Innovación didáctica en Historia: un estado de la cuestión en torno a cuatro ejes temáticos.

Diego Luna Delgado.

\section{Reseñas}

Foster, B. R. (2016), The Age of Agade. Inventing empire in ancient Mesopotamia, Londres y Nueva York: Routledge, 438 págs.

Juan Álvarez García.

Alviz Fernández, M. y Hernández de la Fuente, D. (Eds.) (2017). De ópos a limes: el concepto de frontera en el mundo antiguo y su recepción. Madrid: Escolar y Mayo editores. 256 págs.

Ethan Yepes de la Hoz.

Clares Clares, M ${ }^{\mathrm{a}}$ E. (2017). Música y noches de moda. Sociedades, cafés y salones domésticos de Murcia en el siglo XIX. Murcia: Universidad de Murcia, Servicio de Publicaciones. 474 págs.

Elena Micó Terol 195

Goñi Zabalegui, A. (2018). Género y sociedad en el Egipto romano. Una Mirada desde las cartas de mujeres. Oviedo: Ediciones de la Universidad de Oviedo. 360 págs.

Alejandra Izquierdo Perales. 199

Normas de publicación/Publishing rules 



\title{
La imagen de la Prehistoria en el cine y los géneros del cine prehistórico. Un mundo de hombres mono, bikinis y dinosaurios
}

\author{
The Image of Prehistory in Cinema and the Prehistoric Cinema Genres. A World of
}

Monkey-Men, Bikinis and Dinosaurs.

Lombo Montañés, Alberto ${ }^{1}$

Universidad de Zaragoza

Recibido: 08/03/2019

Aceptado: 19/05/2019

Para citar este artículo: Lombo Montañés, A. (2019). La imagen de la Prehistoria en el cine y los géneros del cine prehistórico. Un mundo de hombres mono, bikinis y dinosaurios. Panta Rei. Revista Digital de Ciencia y Didáctica de la Historia, 9-35.

ISSNe: 2386-8864

DOI: $10.6018 /$ pantarei/2019/01

\begin{abstract}
Resumen
El presente artículo establece las bases de una historia de la Prehistoria en el cine. Se presenta una selección de películas y se ordenan mediante cuatro géneros cinematográficos (comedia, animación, histórico y fantástico). También se analiza el contenido de los films (el hombre prehistórico, la mujer prehistórica y el paisaje). Por último, se reflexiona también sobre las películas que hablan sobre la evolución humana. El resultado de este trabajo resalta tres momentos principales: 1) el origen cómico del cine prehistórico (1905-1940), 2) el intento de estandarización de los estereotipos en el cine fantástico de aventuras (1940-1970), y 3) la tendencia histórica (1980-2019), que incluye un debate acerca del uso de la Prehistoria en la postmodernidad.
\end{abstract}

\section{Palabras clave}

Comedias, dibujos animados, fantasía, ciencia-ficción, evolución.

\section{Abstract}

This article establishes the bases of a history of prehistory in cinema. We have selected some films which are sorted into four genres (comedy, animation, historical and fantastic). We have also analyzed the content of the films (the prehistoric man, the prehistoric woman and landscape). Finally, this article reflects also on films about human evolution in the 21st century. The result of this work highlights three main stages: 1) the comic origin of prehistoric cinema (1905-1940), 2) the attempt at standardization of the stereotypes in the fantastic adventures' films (1940-1970), and 3) the historical tendency (1980-2019), as it includes a discussion about the use of prehistory in postmodernity.

\section{Keywords}

Comedy, cartoon, fantasy, science fiction, evolution.

1 Para contactar con el autor: Alberto Lombo Montañés. Universidad de Zaragoza. albertolomon@hotmail. com. 


\section{Introducción}

El cine ha reflejado la Prehistoria de dos formas principales: a través de (1) películas ambientadas en el periodo prehistórico y (2) películas que aluden a temas prehistóricos, entre las que destacan las que hacen alusión a las teorías de la evolución humana. Las primeras tratan de recrear la Prehistoria durante toda la película o parte de ella y son las más reconocibles. Ellas forman el tipo principal de toda clasificación. De hecho, las segundas pueden considerarse como una variante irregular del cine prehistórico, pero que no podemos ignorar, debido a su trascendencia en el imaginario actual. En cualquier caso, a día de hoy la Prehistoria es reflejada de tantas maneras y en tantos géneros, que hacen muy difícil su clasificación y estudio. A la dificultad de definición de los géneros cinematográficos (Altman, 2000), hay que añadir la tendencia moderna por mezclar y hacer irreconocibles los géneros (Lipovetsky y Serroy, 2009). Teniendo en cuenta estas advertencias es posible realizar una clasificación orientativa de los diferentes tipos de películas, que nos sirva para establecer las bases de una historia de la Prehistoria en el cine. Hemos de destacar que el presente estudio pretende ir más allá de lo que se conoce como "cine prehistórico" propiamente dicho, para examinar otro tipo de films en los que se expresan ideas afines a la Prehistoria (el tipo 2 antes señalado). Estas son películas que no entran en las clasificaciones ordinarias, pero que hoy son fundamentales para entender cómo se usa e imagina la Prehistoria en la postmodernidad. Este es a nuestro juicio uno de los resultados más novedosos de la presente investigación. En cualquier caso, la relación de la Prehistoria con el cine es mucho más importante de lo que se cree y va mucho más allá de su representación ficcional en la pantalla.

\section{Estado de la cuestión}

Cuando en los años ochenta la historia empezaba a profundizar en el estudio del cine histórico, el Paleolítico apenas era mencionado. En cierta medida, no existía un cine histórico de la Prehistoria o al menos no era tan llamativo como podía serlo, por ejemplo, el "cine de romanos", el denominado péplum. En principio, la Prehistoria se encuadraba dentro del "cine de dinosaurios" (Blanco, 1993), "el cine de aventuras" (Kempen, 1994) o el de "monstruos prehistóricos" (Losilla, 1997). El libro de Blanco (1993) nos ofrecía ya una lista de películas a tener en cuenta; pero el artículo de Losilla (1997), insuperable hasta la fecha, nos daba un contexto histórico en el que poder ubicar estas producciones cinematográficas. El magnífico libro de Kempen, estaba más orientado a la literatura y a los medios de comunicación en general (Kempen, 1994). Sin embargo, las películas ambientadas en el periodo paleolítico continuaban sin poder distinguirse de otras en las que solo aparecían dinosaurios o monstruos prehistóricos. El primero en distinguirlas fue Hernández-Descalzo (1997), en un artículo de referencia obligada que ya empezaba a visibilizar e individualizar las películas prehistóricas. Esto tuvo una relevancia fundamental en la percepción y definición de lo que ya empezaba a considerarse como "cine prehistórico" o "cine ambientado en el periodo prehistórico", sembrando un valioso precedente para futuras investigaciones. Bajo este punto de vista, Martín (2006) elaboró un primer ordenamiento cronológico de este tipo de películas, que ha sido recientemente actualizado (Rojano, 2016), pero que contaba con un catálogo precedente mucho más completo, y que sin embargo no suele citarse en la bibliografía (Klossner, 2006). Por su parte, el libro de Klossner (2006), recogía quinientos ochenta y un documentos de la televisión y el cine, teniendo en cuenta todos los géneros, incluso los dibujos animados (Klossner, 2006). Este trabajo no es mencionado en lo que a día de hoy es uno de los mejores análisis del cine prehistórico, realizado desde el Museo de Valencia (Jardón, Pérez y Soler, 2012). En esta obra colectiva, prehistoriadores como Villaverde, nos ofrecen valiosas reflexiones (Villaverde, 2012). Además de estos trabajos, se han abierto distintas maneras de enfocar esta temática. En Francia, Semonsut estudia la recepción pública de la Prehistoria en la prensa, en la televisión, el cine y los manuales escolares (Semonsut, 2013). Actualmente una línea de investigación examina el cine como principal constructor de estereotipos sobre nuestro pasado remoto (Vogel, Randau y Zink, 2017; Horrall, 2018). Incluso, se ha destacado su influencia en los 
estudiantes universitarios españoles (Egea y Arias, 2015). También los arqueólogos han tratado diversos temas como son las distorsiones de los films en relación a la disciplina científica (Carvajal, Hernando, Soto y Tejerizo, 2011; González, 2018; Tejerizo, 2011), o los puntos en común (Ruiz y Castaño, 2008), se han realizado análisis de una película (García-Escárzaga, 2013) o las reseñas comentadas (Ayán, 2017; Lombo 2014, 2015; Lombo y Alcolea, 2016), e incluso se han analizado las relaciones entre el arte paleolítico y el cine (Azéma, 2011). Sin embargo, el objetivo del presente trabajo es el de profundizar en la historia de los géneros del cine prehistórico, pues es necesario insertar en un discurso histórico los films descritos en los estudios precedentes.

Así pues, pretendemos, a través de ese gran difusor de mitos que es el cine, comprender cómo la gente de hoy imagina la Prehistoria. Por lo tanto, no nos limitaremos solo a las películas que tratan de recrear el periodo prehistórico, sino también aludiremos a las películas actuales que usan conceptos propios de la disciplina, como el de la evolución humana. De esta manera, intentaremos saber cómo el imaginario actual utiliza las teorías evolutivas en el nuevo contexto postmodernista. Solo así podemos entender mejor lo que deberíamos empezar a denominar "Prehistoria postmoderna". Podríamos definir este concepto como el imaginario prehistórico actual, que opera dentro del paradigma tecnológico del siglo XXI, y que hace hincapié, sobre todo, en las teorías de la evolución. En resumen, consideran que el ser humano puede seguir evolucionando a una nueva humanidad, que algunos pensadores llaman posthumanidad (Ferry, 2017). Por otro lado, el cine cuenta ya con algunas películas dignas de considerarse históricas (p.e. En busca del fuego, La guerre du feu, Jean Jacques Arnaud, 1981; Alpha, Albert Hughes, 2018). Además el auge de cine de animación prehistórico desde el éxito de La Edad del Hielo (Ice Age, Chris Wedge y Carlos Saldanha, 2002) y obras maestras como La cueva de los sueños olvidados (Cave of Forgotten Dreams, Wegner Herzog, 2010), hacen cada vez más necesario investigar el origen y el desarrollo de la Prehistoria en el cine.

\section{Método}

Para elaborar esta historia de la Prehistoria en el cine, nos centraremos sobre todo en los films ambientados en el periodo paleolítico, es decir, películas de "cavernícolas", homínidos, pero también las que hablan sobre la evolución humana, principalmente. Dejamos a un lado las cintas que aluden a periodos post-paleolíticos, como por ejemplo las del tipo Conan, el bárbaro (Conan the Barbarian, John Milius, 1982), La conquista de la tierra perdida (Conquest, Lucio Fulci, 1983), etc., porque parecen tener una idiosincrasia distinta y merecerían un estudio aparte. Luego, nos referimos a una Prehistoria "paleolítica", o si se prefiere una Edad de Piedra, que el cine dibuja como un tiempo de hombres mono, bikinis y dinosaurios. Incluimos en este estudio todos los géneros, desde los dibujos animados a las películas fantásticas de ciencia-ficción. Hasta aquí el repertorio de películas analizado responde al de los trabajos mencionados. Finalmente también queremos llamar la atención sobre el fenómeno de diversificación que la Prehistoria sufre en el presente siglo. En concreto, prestaremos atención en cómo las teorías de la evolución humana se presentan en muchos films de ciencia-ficción, como por ejemplo en el cine de superhéroes, que a menudo parecen ser el resultado de un nuevo paso en la evolución humana. Esta "Prehistoria postmodernista", que relaciona la evolución con el nuevo hombre posthumano, es fundamental para entender el papel de la Prehistoria en la mentalidad moderna. Así pues, distinguiremos los films prehistóricos de los que usan conceptos propios de la Prehistoria. De este modo podremos no solo analizar cómo se ha reflejado el mencionado periodo en la historia del cine, sino cómo los conceptos propios de la ciencia prehistórica forman parte de $-\mathrm{y}$ se diluyen en- el imaginario fílmico de la sociedad actual. Así, conseguiremos tener un panorama amplio y preciso de la influencia que esta disciplina científica tiene en el mundo presente. Porque si en el presente siglo las ideas de la evolución se adaptan a los posthumanismos, es porque la Prehistoria hoy se encuentra diluida en un sinfín de temas que es preciso analizar. Por consiguiente, mencionaremos todo tipo de películas que nos permitan profundizar en el estudio de las relaciones entre la Prehistoria y el cine. A parte de estas películas,

Panta Rei (2019), 9 - 35 
hemos realizado una lista de films clasificándolos en géneros (Tabla 1). Hemos establecido cuatro géneros (comedia, animación, histórico y fantástico) que no pretenden ser exhaustivos, entre otras cuestiones porque este es un tema muy debatido por los especialistas (Altman, 2000). Estos cuatro grupos nos ayudan a ordenar el material de forma bastante coherente. Las películas cómicas y las animadas se distinguen bien y no presentan tantos problemas como a la hora de catalogar los films fantásticos o de ciencia-ficción. Para no complicar más la cosa, hemos dividido el género fantástico en tres subgéneros: aventura $(A)$, ciencia-ficción $(C-F)$ y terror $(T)$. Por otro lado, el género histórico ha sido magníficamente definido por Villaverde (2012). En este grupo incluimos también algunas películas de cierto talante realista en donde, en nuestra opinión, se encuentran las raíces del género. En definitiva, la Prehistoria reflejada en el cine, depende de la época y el tipo de film que lo produce, es decir, del género. Este es el motivo por el cual hemos ordenado cronológicamente, en una breve historia, los géneros mencionados, lo cual nos ha permitido analizar el contenido de las películas y destapar algunos tópicos en relación con los estereotipos masculinos, femeninos y la geografía. Queda por último, discutir si el enfoque utilizado en el presente estudio es pertinente o no, si debemos acotar el sentido de lo que consideramos como cine prehistórico o debemos ampliarlo para analizar todo tipo de materiales. En nuestra opinión, el presente actual nos obliga a perdernos en un mundo de ciencia ficción (Bourget, 1992, p. 32), una especie de metahistoria, en donde el apocalipsis es presentado como un extraño retorno a la Prehistoria.

\section{Tabla 1}

Listado de películas seleccionadas y su clasificación mediante géneros. En minúsculas se recogen también los siguientes códigos: películas en las que aparecen hombres-mono (HM), películas de bikinis (B), películas de dinosaurios (D), películas que aluden a la evolución en contextos postmodernos (E). Si las siglas se combinan, por ejemplo B/D, significa que se trata de una película de bikinis y dinosaurios. Se distinguen tres subgéneros: aventura $(A)$, ciencia-ficción $(C-F)$ y terror $(T)$.

\begin{tabular}{|c|c|c|c|}
\hline Película (Título original) (código) & Director & Año & Género \\
\hline Prehistoric pepes ${ }^{(\mathrm{D})}$ & Lewin Fitzhamon & 1905 & Animación \\
\hline The prehistoric man (D) & Walter R. Booth & 1908 & Animación \\
\hline La civilization a travers les âges & Georges Méliès & 1908 & Histórico \\
\hline Man's Genesis (HM/D) & David. W Griffith & 1912 & Histórico \\
\hline The cave man & $\begin{array}{l}\text { Charles L. Gaskill /Ralph } \\
\text { Ince }\end{array}$ & 1912 & Histórico \\
\hline Brute force $(\mathrm{HM} / \mathrm{D})$ & David. W Griffith & 1914 & Histórico \\
\hline His prehistoric past & Charles Chaplin & 1914 & Comedia \\
\hline The cave man & Theodore Marston & 1915 & Comedia \\
\hline Prehistoric poultry (D) & Willis H. O’Brien & 1916 & Animación \\
\hline R.F.D. 10000 BC (D) & Willis H.O. Brien & 1916 & Animación \\
\hline The cave girl & Joseph Franz & 1921 & Fantástico $(A)$ \\
\hline The first circus ${ }^{(H M)}$ & $\begin{array}{c}\text { Herbert M. Dawley / Tony } \\
\text { Sarg }\end{array}$ & 1921 & Animación \\
\hline His prehistoric blunder & Craig Hutchinson & 1922 & Comedia \\
\hline Three ages ${ }^{(D)}$ & Buster Keaton & 1923 & Comedia \\
\hline The lost world (D) & Harry H. Hoyt & 1925 & Fantástico (A) \\
\hline The caveman (HM) & Lewis Milestone & 1926 & Fantástico $(\mathrm{T})$ \\
\hline Flying elephants & Frank Butler & 1928 & Comedia \\
\hline King Kong & Cooper y Schoedsack & 1933 & Fantástico $(\mathrm{T})$ \\
\hline
\end{tabular}


Cave man (D)

One million B.C. ${ }^{(D)}$

The ape man ${ }^{(H M)}$

Return of the ape man (HM)

Prehistoric Women ${ }^{(\mathrm{B} / \mathrm{HM})}$

El bello durmiente

The neandertal man ${ }^{(\mathrm{HM})}$

Cesta do Praveku

The land unknown (D)

Teenage caveman ${ }^{(D)}$

The wild women of Wongo ${ }^{(B)}$

The lost word (D)

The time machine ${ }^{(H M)}$

Valley of the dragons $(\mathrm{D} / \mathrm{HM})$

Eegah (HM)

Maciste contro i mostri (D)

La edad de piedra (D)

One millions years B.C. ${ }^{(D / B)}$

Women of the prehistoric planet ${ }^{(D)}$

La isla de los dinosaurios ${ }^{(D)}$

Slave girls ${ }^{(B)}$

Voyage to the planet of the prehistoric women ${ }^{(\mathrm{D})}$

Planet of the apes ${ }^{(H M)}$

2001: a space odyssey ${ }^{(\mathrm{HM})}$

When dinosaurs ruled the earth $(\mathrm{D} / \mathrm{B})$

Quando le donne avevano la coda ${ }^{(B)}$

Creatures the world forgot $(\mathrm{B} / \mathrm{D})$

Quando gli uomini amarano la clava... e con le donne fecero dindon ${ }^{(B)}$

Hijazo de mi vida

Quando le donne persero la coda ${ }^{(B)}$

Schlock (HM)

The people that time forgot $(\mathrm{D})$

Altered States ${ }^{(E)}$

Caveman (D)

History of the world

La guerre du feu ${ }^{(H M)}$

Grunt (B/D)

II mondo di Yor ${ }^{(\mathrm{HM})}$

La guerra del Ferro ${ }^{(H M)}$

$\begin{array}{ccc}\text { Ub Iwerks } & 1934 & \text { Animación } \\ \text { Hal Roach } & 1939 & \text { Fantástico (A) } \\ \text { William Beaudine } & 1943 & \text { Fantástico (T) } \\ \text { Philp Rosen } & 1944 & \text { Fantástico (T) } \\ \text { Gregg C. Tallas } & 1950 & \text { Fantástico (A) } \\ \text { Gilberto Martínez Solares } & 1952 & \text { Comedia } \\ \text { Ewald André Dupont } & 1953 & \text { Fantástico (T) } \\ \text { Karel Zeman } & 1955 & \text { Fantástico (A) } \\ \text { Virgil W. Vogel } & 1957 & \text { Fantástico (A) } \\ \text { Roger Corman } & 1958 & \text { Fantástico (A) } \\ \text { James L. Wolcott } & 1958 & \text { Fantástico (A) } \\ \text { Irvin Allen } & 1960 & \text { Fantástico (A) } \\ \text { George Pal } & 1960 & \text { Fantástico (C-F) } \\ \text { Edward Bernds } & 1961 & \text { Fantástico (A) } \\ \text { Arch Hall Sr. } & 1962 & \text { Fantástico (T) } \\ \text { Guido Malatesta } & 1963 & \text { Fantástico (A) } \\ \text { René Cardona } & 1964 & \text { Comedia } \\ \text { Don Chaffey } & 1966 & \text { Fantástico (A) } \\ \text { Arthur C. Pierce } & 1966 & \text { Fantástico (C-F) } \\ \text { Rafael Portillo } & 1966 & \text { Fantástico (A) } \\ \text { Michael Carreras } & 1967 & \text { Fantástico (A) } \\ \text { Peter Bogdanovich } & 1968 & \text { Fantástico (C-F) } \\ \text { Franlin J. Schaffner } & 1968 & \text { Fantástico (C-F) } \\ \text { Stanley Kubrick } & 1968 & \text { Fantástico (C-F) } \\ \text { Val Guest } & 1970 & \text { Fantástico (A) } \\ \text { Don Chaffey } & 1970 & \text { Comedia } \\ \text { Bruno Corbucci } & 1971 & \text { Fantástico (A) } \\ \text { Costa Campanile } & 1970 \text { Comedia }\end{array}$

1971

1972

1973

1977

1980

1981

1981

1981

1983

1983

1983
Comedia

Comedia

Comedia

Fantástica $(\mathrm{A})$

Fantástica (C-F)

Comedia

Comedia

Histórico

Comedia

Fantástica (C-F)

Fantástica $(\mathrm{A})$ 
Iceman

Cavegril (B)

The clan of the cave bear

Missink link (HM)

A nymphoid Barbarian in dinosaur hell ${ }^{(D / B)}$

Encino man

The Flinstones ${ }^{(D)}$

Being human

Dinosaur valley girls ${ }^{(B / D)}$

The Flinstones in Viva Rock Vegas (D)

$$
\begin{aligned}
& \text { X-Men } \\
& \text { Ice }
\end{aligned}
$$

RRRrrr!!!

Bikini grils on dinosaur planet ${ }^{(B / D)}$

Homo erectus ${ }^{(B)}$

A.R.O.G

10.000 BC ${ }^{(\mathrm{D} / \mathrm{B})}$

Year one

Cave of Forgotten Dreams

Ao, le dernier neandertal

The Croods (D)

Lucy ${ }^{(E)}$

The Good Dinosaur (D)

Altamira

Split (E)

Arg Stairs

Early Man

Alpha

Fuente: elaboración propia.

\begin{tabular}{ccc} 
Fred Schepisi & 1984 & Fantastica (C-F) \\
David Oliver & 1985 & Comedia \\
Michael Chapman & 1986 & Histórico \\
Carol Hughes & 1988 & Histórico \\
Brett Piper & 1991 & Fantástico (C-F) \\
& & \\
Les Mayfield & 1992 & Comedia \\
Briant Levant & 1994 & Comedia \\
Bill Forsyth & 1994 & Comedia \\
Donald F. Glut & 1996 & Comedia \\
Briant Levant & 2000 & Comedia \\
& & \\
Bryan Signer & 2000 & Fantástico (C-F) \\
Chris Wedge / Carlos & 2002 & Animación \\
Saldanha & & \\
Alain Chabat & 2004 & Comedia \\
William Hellfire & 2005 & Comedia \\
Adam Rifkin & 2007 & Comedia \\
Ali Taner Baltraci & 2008 & Comedia \\
Roland Emmerich & 2008 & Fantástico (A) \\
Harold Ramis & 2009 & Comedia \\
Werner Herzog & 2010 & Histórico \\
Jacques Malaterre & 2010 & Histórico \\
Chris Sanders y Kirk & 2013 & Animación \\
DeMicco & & \\
Luc Besson & 2014 & Fantástico (C-F) \\
Peter Sohn & 2015 & Animación \\
Hugh Hudson & 2016 & Histórico \\
Night Shyamalan & 2016 & Fantástico (C-F) \\
Kyle Romanek & 2017 & Comedia \\
Nick Park & 2018 & Animación \\
Albert Hughes & 2018 & Histórico \\
\hline & &
\end{tabular}

1984

1985

1986

1992

1994

2000

2004

2005

2008

2009

2010 Histórico

\section{Breve historia de la Prehistoria en el cine}

\section{1. El cine cómico prehistórico}

El origen de la Prehistoria fílmica es cómico. La primera película, hoy lamentablemente perdida, es una adaptación del cómic de E. T. Reed, Mr Punch's Prehistoric Peeps, de 1894, titulada igualmente Miradas a la Prehistoria (Prehistoric Peeps, Lewin Fitzhamon, 1905). El profesor Chump (Sebastian Smith) sueña con la Prehistoria. Es perseguido por monstruos prehistóricos y, como no, se encuentra rodeado de mujeres prehistóricas, antes de que su esposa le despierte. La segunda película cómica que queremos mencionar es Charlot prehistórico (His prehistoric past, Charlie 
Chaplin, 1914), y pertenece a la llamada comedia burlesca o slapstick. De la misma manera que en el anterior film, Charlot se queda dormido en el banco de un parque y sueña con un grupo de mujeres prehistóricas que forman el harén del típico hombre bruto (Figura $1 \mathrm{~A}$ ). En este corto no aparecen dinosaurios y Charlot inventa nuevas bromas, pedradas, mazazos y caídas por acantilados que se observan en cintas posteriores. En 1915 se realiza la primera adaptación cinematográfica de la obra de teatro de Gelette Burges El hombre de las cavernas, un film hoy perdido (The Caveman, Theodore Marston, 1915) aunque tiene otra versión (De carbonero a gran señor, The Caveman, Lewis Milestone, 1926). Pero, una de las mejores comedias que se ha realizado sobre la Prehistoria en el cine, es la primera parte de Las tres edades (The Three Ages, Buster Keaton y Edward Cline, 1923). En este film, el protagonista (Buster Keaton) aparece montado encima de un brontosaurus (Figura $1 \mathrm{~B}$ ), como en muy al estilo de los primeros Punch ingleses de Reed o las tiras cómicas de Frederick Burr Opper (Our Antediluvian Ancestors, 1901). Keaton pelea contra el habitual bruto por una chica a pedradas, garrotazos, caídas por barrancos y acrobacias típicas del estilo burlesco (Figura $1 \mathrm{C}$ ). Otra comedia realizada por el gordo y el flaco (Elefantes voladores, Flying Elephants, Frank Butler, 1927), cierra lo que podríamos llamar "la edad de oro del cine cómico prehistórico". Laurel y Hardy buscan esposa y se las tienen que ver con maridos celosos a base de golpes. Este tipo de cine está muy ligado a la animación gráfica en general y por ende a los dibujos animados. Hay una llamativa ausencia de comedias prehistóricas tras la crisis de 1929 y la Segunda Guerra Mundial. Todo se paraliza, hasta que los nuevos impulsos tecnológicos de los años sesenta en EEUU permiten otra vez gastar bromas con el periodo de la industria pétrea. En La edad de piedra (René Cardona, 1964), se deja sentir la influencia de la serie de dibujos animados Los Picapiedra (The Flintstones, William Hanna y Joseph Barbera, 1960-1966). Como veremos, ambos géneros están estrechamente relacionados. En los años setenta el cine cómico prehistórico entra en la órbita del mundo hippie. En Italia se realizan comedias populares de relativo éxito nacional como Cuando las mujeres tenían cola (Quando le donne avevano la coda, Pascale Festa Campanile, 1971), que tuvo una segunda parte en Cuando las mujeres perdieron la cola (Quando le donne persero la coda, Pascale Festa Campanile, 1972) y Cuando los hombres usaban cachiporra y con las mujeres hacían "ding-dong" (Quando gli uomini amarano la clava...e con le donne fecero din-don, Bruno Corbucci, 1972). Se hacen parodias de los gorilas asesinos (El monstruo de las bananas, Schlock, John Landis, 1973) o de los dinosaurios monstruosos (Cavernícola, Caveman, Carl Gottlieb, 1981). En los años ochenta, se recupera algo de la calidad de los primeros tiempos en la parte primera de La loca historia del mundo (History of the World, Mel Brooks, 1981). Las producciones aumentan porque estas películas son relativamente fáciles de hacer y tienen cierta acogida popular. A medida que las sociedades se acomodan, los contrastes con la Edad de Piedra se hacen más palpables. En los años noventa, la serie de dibujos de Pedro Picapiedra y compañía se pasa a la pantalla (Los Picapiedra, The Flintstones, de Brian Levant, 1994) y su precuela (Los Picapiedra en Viva Rock Las Vegas, The Flintstones in Viva Rock Vegas de Brian Levant, 2000). En el nuevo siglo, las comedias prehistóricas encuentran un mercado factible en diversos países como Francia (Caverrrnicola!, Alain Chabat, 2004), EE UU (Homo erectus, Adam Rifkin, 2007, Año Uno, Year One de Harold Ramis, 2009), Turquía (A.R.O.G, Ali Taner Baltraci, 2008), Rumania (Arg Stairs, Kyle Romanek, 2017) y en España, con cortometrajes como Alcachofas piraña del abismo prehistórico, de Javier Lozano Sánchez, 2014. En la actualidad, algunas comedias que no tienen que ver con el periodo estudiado, recurren al estereotipo del "cavernícola", como los neandertales de Noche en el museo (Night at the Museum, Shawn Levy, 2006). 


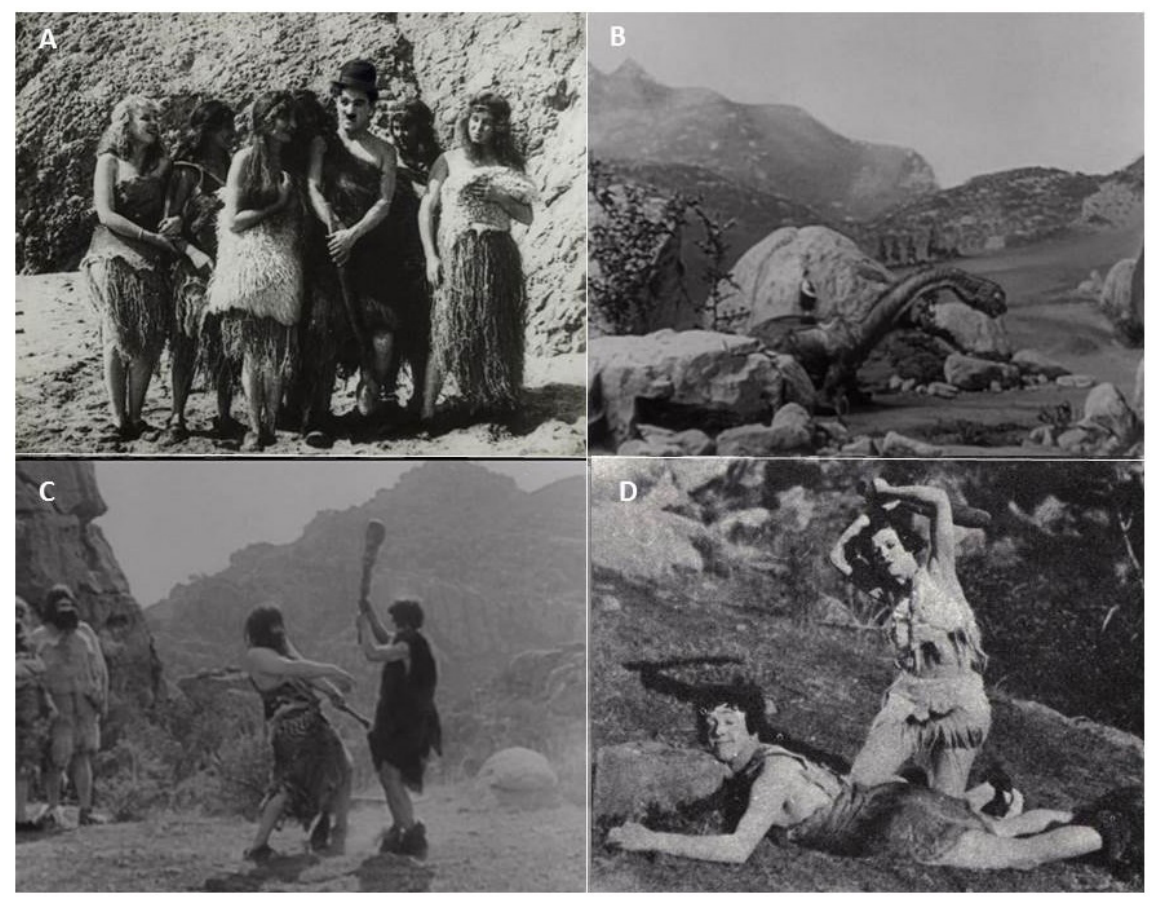

Figura 1: A) Charlot rodeado de mujeres prehistóricas (Charlot prehistórico, His prehistoric past, Charlie Chaplin, 1914). B) Prehistórico subido a lomos de un brontosaurus (Las tres edades, The Three Ages, Buster Keaton y Edward Cline, 1923). C) Buster Keaton en un duelo a garrotazos por la chica (Las tres edades, The Three Ages, Buster Keaton y Edward Cline, 1923). D) El flaco apaleado por una mujer prehistórica (Elefantes voladores, Flying Elephants, Frank Butler, 1927).

\subsection{El cine de animación prehistórico}

La historia del cine de animación presenta concomitancias con el género cómico debido a su carácter eminentemente lúdico. Además también se encuentra influido por las tiras cómicas, incluso el primer cortometraje es realizado por un famoso dibujante (Gertie, the Dinosaur, Winsor McCay, 1914) aunque el primer film de animación es anterior (The prehistoric man, Walter R. Booth, 1908). Se trata de un corto en el que un hombre prehistórico y un animal, que acaba tragándoselo, salen del cuadro de un artista. Posteriormente, entra en escena el gran Willis O'Brien con su famosa técnica de animación de muñecos stop motion, fotograma a fotograma (Prehistoric Poultry, Willis O'Brien, 1916). Esta película dura unos cuatro minutos y presenta al típico cavernícola con garrote y pieles que convive con dinosaurios domésticos (Figura $2 \mathrm{~B}$ ) y el dinornis (ancestro de la gallina prehistórica). Esta especie de avestruz gigante se lo come todo al estilo de los dinosaurios de las tiras cómicas de Opper (Our Antediluvian Ancestors, 1901). Otro corto del mismo director es R.F.D. 10000 BC (Willis O'Brien, 1916), pues dura unos doce minutos aproximadamente. El cartero prehistórico conduce un carro tirado por un dinosaurio (Figura $2 \mathrm{~A}$ ), algo que ya habíamos visto en las tiras cómicas mencionadas. Algunas escenas del corto animado de O'Brien influirán en el largometraje de Keaton: por ejemplo, el tema de la pelea con un forzudo y el uso de las flores para conseguir a la chica. Al final, el cartero sale volando partido en dos, pero sus piernas aún logran andar sin cuerpo ni cabeza hasta reunirse con su otra mitad. Finalmente, The first circus (Herbert M. Dawley y Tony Sarg, 1921), es un cortometraje de siluetas animadas (cartones) rodado en plena ley seca. Por eso los homínidos descubren el alcohol. De nuevo aparecen los humanos (más parecidos a pigmeos), domesticando dinosaurios en un circo y una recreación de Stonehenge. Pero, como ocurría en las comedias, el cine de animación se interrumpe en las tres décadas siguientes. Aunque aparecen a veces alusiones en cortos de dibujos (Prehistoric Porky, Robert Clampett, 1940; Caveman Inki, Chuk Jones, 1950), 
solo se reactiva en los años sesenta con la serie de Los Picapiedra. En esta época hay cortos de dibujos animados en la televisión (La Pantera Rosa en Rosa Prehistórico, Prehistoric Pink, Hawley Pratt, 1968), pero no en las grandes producciones, dominadas por Walt Disney. El auge del cine de dibujos animados prehistórico se produce en el presente siglo, con el éxito de La Edad del Hielo (Ice Age, Chris Wedge y Carlos Saldanha, 2002). Este film es la primera gran producción de dibujos animados sobre la Prehistoria asesorada científicamente. No aparecen dinosaurios, aunque se bromea con ellos, y a pesar de que tiene sus lógicas licencias (el tigre dientes de sable, llevaba extinguido medio millón de años), es un ejemplo de lo que la colaboración científica puede aportar al cine. En este sentido, es curioso que la mejor película de la saga, que ha iniciado un fenómeno sin precedentes en la historia del cine prehistórico de dibujos animados, sea la única que se molestó en documentarse. El resto de la serie (Ice Age 2 el deshielo, Ice Age: The Meltdown, Carlos Saldanha, 2006; Ice Age 3. El origen de los dinosaurios, Ice Age: Dawn of the Dinosaurs, Carlos Saldanha y M. Thurmeier, 2009 e Ice Age 4: La formación de los continente, Ice Age 4: Continental Drift, S. Martino y M. Thurmeier, 2012), se aleja bastante de la calidad de la primera. Igualmente los mismos tópicos sobre el hombre bruto se siguen difundiendo a los niños en Los Croods: Una aventura prehistórica (The Croods, Chris Sanders y Kirk DeMicco, 2013) y Cavernícola (Early Man, Nick Park, 2018), donde unas tribus de diferentes periodos prehistóricos juegan al futbol. El hombre con garrote y pieles es el icono predilecto del imaginario prehistórico, que aparece en dibujos animados de todo tipo (Horton, Horton Hears a Who!, Jimmy Hayward y Steve Martino, 2008; Los Minions, Minions, Pierre Coffin y Kyle Balda, 2015). Este icono, cuyo exponente más conocido es Pedro Picapiedra, ha sido popularizado por las tiras cómicas y es el retrato robot de nuestro antepasado prehistórico, que todo niño tiene en mente.

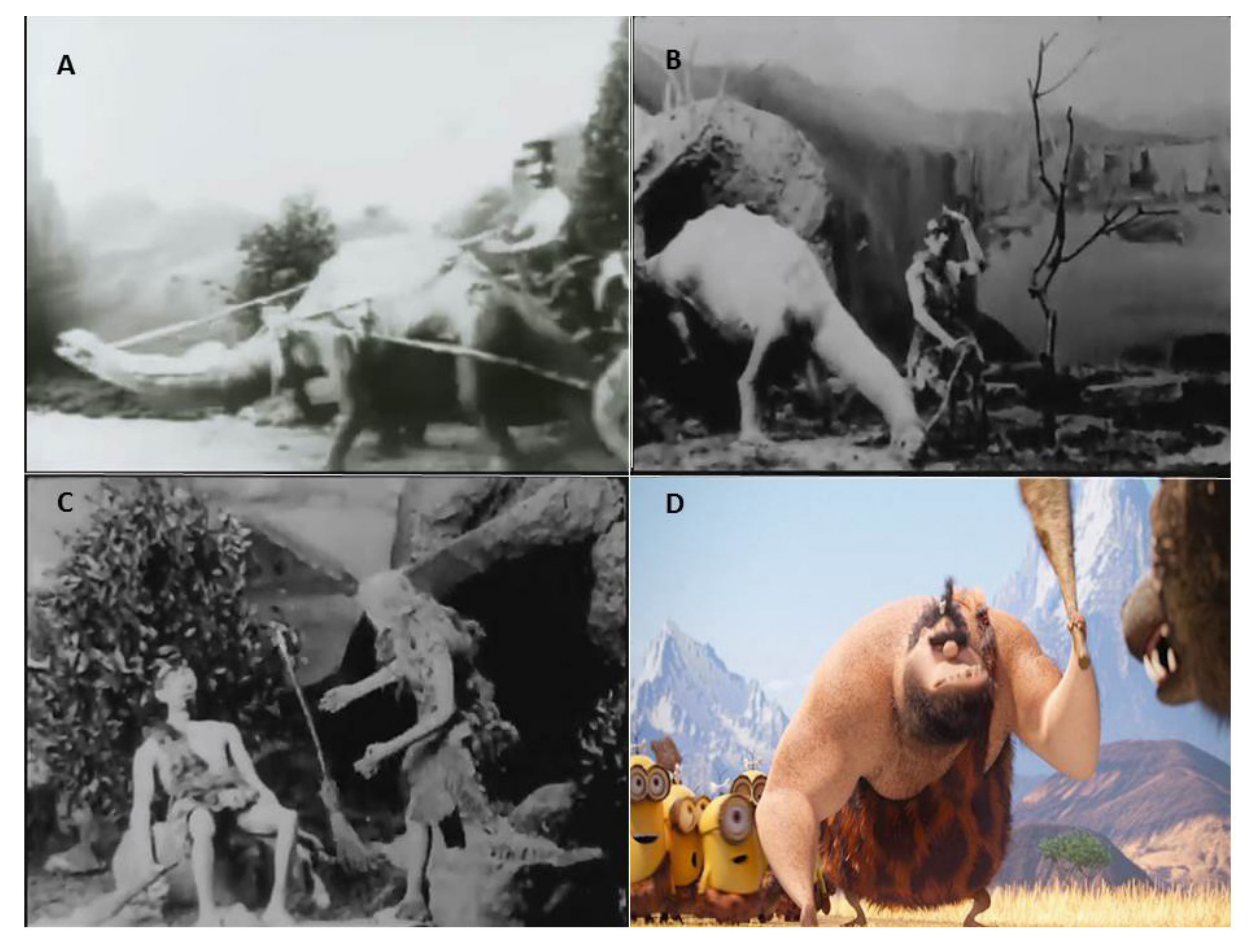

Figura 2: A) Carro tirado por dinosaurio (R.F.D. 10000 BC, Willis O'Brien, 1916). B) Dinosaurio doméstico (Prehistoric Poultry, Willis O'Brien, 1916). C) Hombre y mujer (que acaba de dejar la escoba) prehistóricos

(Prehistoric Poultry, Willis O'Brien, 1916). D) Icono del hombre bruto cavernícola (Los Minions, Minions, Pierre Coffin y Kyle Balda, 2015). 


\subsection{El cine realista o histórico prehistórico}

Las primeras aproximaciones con ciertas pretensiones realistas al periodo prehistórico son versiones creacionistas (La civilización a través de las edades, La civilisation à travers les âges, Georges Méliès, 1908) o recreaciones basadas en los prejuicios decimonónicos sobre el progreso humano. A esta última categoría pertenecen los dos cortometrajes de Griffith. En el primero, el personaje principal inventa la maza de piedra (La génesis del hombre, Man's génesis, D. W. Griffith, 1912) y en el segundo el arco (Figura 3 B), señalando así el triunfo del cerebro frente a la fuerza bruta (La vida del hombre primitivo, Brute force, 1914). Es decir, se muestra un progreso lineal de la técnica y de los inventos, que han conducido al hombre (blanco) occidental a la supuesta cumbre de la evolución. Por otro lado, en La vida del hombre primitivo se recurre al sueño de un hombre como forma de viaje a la Prehistoria tal y como hemos visto en Prehistoric Peeps y luego en Charlot ${ }^{2}$. En los cortos de Griffith (en realidad son dos partes) se narra la historia de dos tribus, una de las cuales es de aspecto simiesco (Figura $3 \mathrm{~A}$ ). La serie funciona en base a las peleas, persecuciones, raptos de mujeres y algún dinosaurio que otro. Las ideas que se reflejan son el ocio, la competencia sexual y la animalidad (hasta los niños tienen pelo en la espalda), que contrastan con el mundo civilizado. Llama la atención que los inventos sean armas (mazas, arcos y flechas), como si el progreso humano fuera exclusivamente armamentístico. Al parecer hay otro film del mismo estilo dramático (The cave man, Charles L. Gaskill y Ralph Ince, 1912) realizado para la Vitegraph, que no hemos podido ver. Estas primeras aproximaciones, no sé si llamarlas realistas, al mundo prehistórico, acabarán desembocando en otros géneros (aventura, ciencia-ficción e incluso terror), que utilizarán el modelo narrativo ideado por Griffith. Es cierto pues que no hay prácticamente películas históricas de la Prehistoria y que películas fantásticas como Viaje a la Prehistoria (Cesta do praveku, Karel Zeman, 1954) son más históricas que las propias históricas. Así pues, lo histórico en el cine prehistórico no se desarrolla en este género precisamente, sino más bien en el realismo y las reconstrucciones cada vez más necesarias en otros géneros. Por lo tanto, no se puede hablar de cine histórico prehistórico propiamente dicho, como bien ha señalado Villaverde (2002), hasta la aparición de En busca del fuego (La guerre du feu, Jaques Arnaud, 1981). Este film basado en la novela homónima de Rosny (1911), señala un hito, frecuentemente advertido por los prehistoriadores, en la representación de la Prehistoria. El éxito de las sagas novelísticas, bastante bien documentadas, como las de Auel, estimula a los cineastas a adentrarse un poco en el campo de la reconstrucción histórica ( $E l$ clan del oso cavernario, The clan of the cave bear, Michael Chapman, 1986). Se aprecia en este momento cierta curiosidad por conocer cómo vivieron realmente nuestros antepasados. Esto abrió el camino a documentalistas como Malaterre (Ao, le dernier neandertal, Jacques Malaterre, 2010) y sobre todo al gran Herzog (La cueva de los sueños olvidados, Cave of Forgotten Dreams, Wegner Herzog, 2010). El mago de Baviera, nos invita a soñar con documentos arqueológicos reales. Por primera vez en la historia del cine prehistórico, la Prehistoria real se nos muestra infinitamente más interesante que cualquier relato exótico sobre la brutalidad del mundo primitivo, bikinis y dinosaurios incluidos. Esta película ha influido en Altamira, el origen del arte, José Luis López Linares, 2019 y Altamira, Hugh Hudson, 2016. La última producción que a día de hoy puede incluirse en este epígrafe es otro film valiosamente asesorado (Alpha, Albert Hughes, 2018). El argumento de Alpha, cuyo tema es el aprendizaje de un joven llamado Keda, se asemeja al de las novelas de Elisabeth Marsall Thomas (Fernández, 1991). Esta película recrea el periodo solutrense gracias a la valiosa ayuda de los efectos digitales. En Alpha, la historia y el hiperrealismo de las imágenes se dan la mano en una nueva versión histórica de la realidad.

2 La idea de sueño como medio de viaje a la Prehistoria la encontramos por primera vez en un relato del libro Paris avant I'histoire (1885) titulado "Le rêve" del escritor Élie Bertiet (Richard, 2008). 


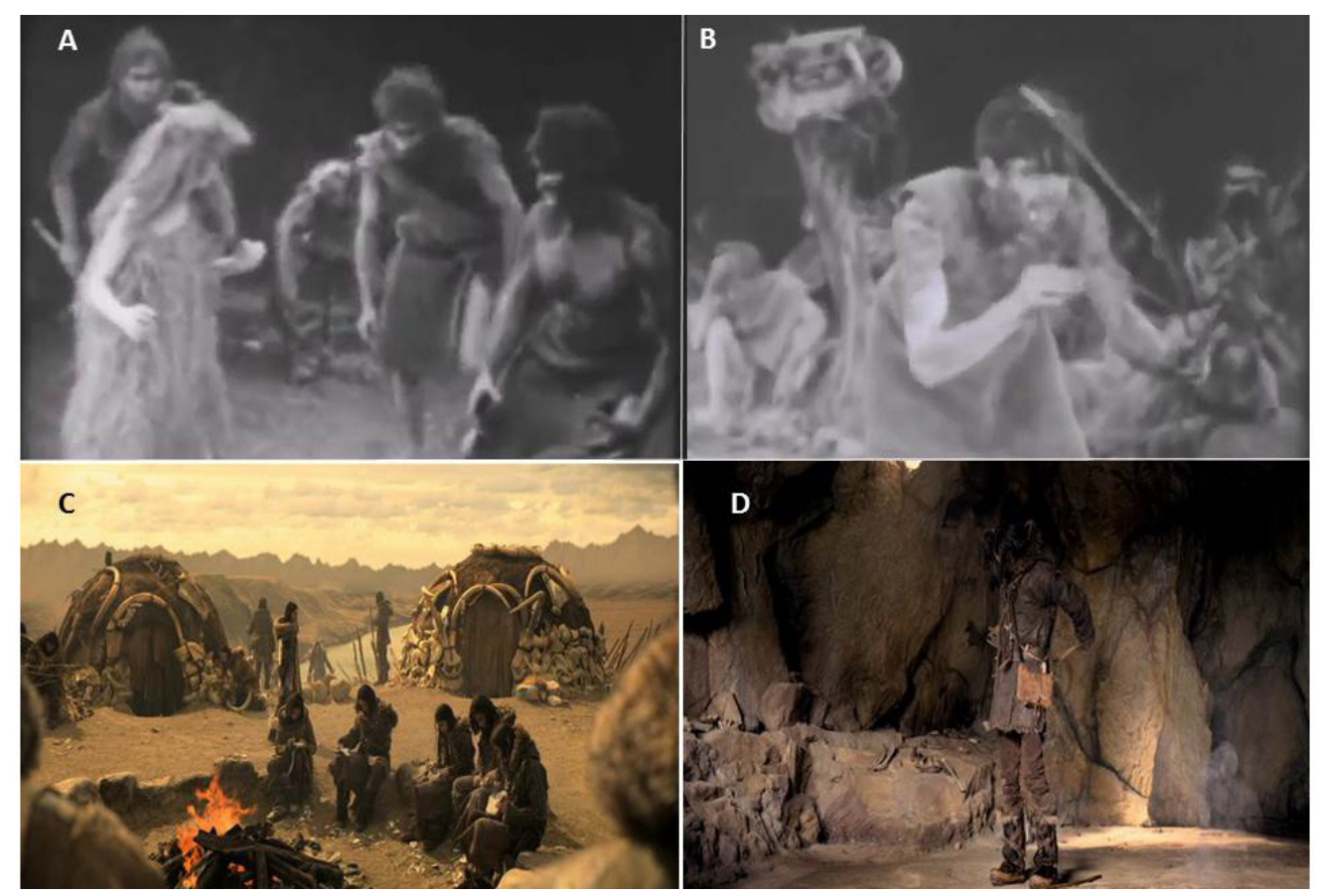

Figura 3: A) Cavernícolas a punto de raptar a la chica (La vida del hombre primitivo, Brute force, 1914). B) El descubrimiento del arco (La vida del hombre primitivo, Brute force, 1914). C) Reconstrucción de los hogares (Alpha, Albert Hughes, 2018). D) Keda vistiéndose en una cueva que tiene al fondo recreaciones del arte paleolítico (Alpha, Albert Hughes, 2018).

\subsection{El cine fantástico y de ciencia-ficción prehistórica}

El cine fantástico prehistórico, sobre todo el de ciencia-ficción, es sin duda el preferido por la cultura popular. La exitosa Hace un millón de años (One Million B.C., Hal Roach, 1939) crea un nuevo tipo de películas que si bien buscan cierto verismo, se decantan por la ciencia-ficción de aventuras. Además de asentar a los dinosaurios como atractivo fundamental, introduce la catástrofe que, en forma de volcanes o terremotos, es un requisito fundamental en este tipo de películas (Maciste contra los monstruos, Maciste contro i mostri, Guido Malatesta, 1962; Hace un millón de años, One Million B.C., Don Chaffey, 1966; Cuando los dinosaurios dominaban la tierra, When Dinosaurs Ruled the Earth, Val Guest, 1970; Criaturas olvidadas del mundo, Creatures the World Forgot, Don Chaffey, 1971; 10000 A.C., 10000 B.C., Roland Emmerich, 2008). Los dinosaurios se introducen en el cine prehistórico también de la mano de Julio Verne (El mundo perdido, The lost world, Harry O Hoyt, 1925) y en la extraordinaria Viaje a la Prehistoria (Cesta do praveku, Karel Zeman, 1954). Otro tipo de películas de corte tarzanesco explotan el mito de las Amazonas (Mujeres prehistóricas, Prehistoric Woman, Gregg Tallas, 1950). En este film no hay dinosaurios, pero sí terroríficos hombres-mono y danzas erótico-femeninas, que se convertirán en otro incansable estereotipo (Las mujeres salvajes del Wongo, The Wild Women of Wongo, James L. Wolcott, 1958; Mujeres prehistóricas, Prehistoric Woman, Michael Carreras, 1967). Estas fantasías eróticas de mujeres salvajes, que también tuvieron su repercusión en los comics prehistóricos (Soler, 2016), hunden sus raíces en los seriales de Edgard Rice Burroughs, como The Cave Girl (1913).

Por último, debemos mencionar algunas "películas de homínidos" que tienden al cine de terror. Los hombres-mono suelen tener apariciones esporádicas en films de diversos géneros, pero sobre todo a partir de King Kong, Merian C. Cooper, Ernest B. Schoedsack, 1933, se populariza el tema del "gorila asesino", cuya iconografía se remonta a las estatuas de Frémiet (1887). Nos referimos a la estatua de un gorila gigante raptando a una mujer (Figura 7 A). Esta es la representación de los impulsos violentos encarnados -y ocultos- en el cuerpo del simio humano o del humano simio, 
es decir, un animal cuya morfología nos es familiar porque es en esencia la nuestra. El cuerpo de King Kong, no deja de ser un indeseable recuerdo del nuestro, el fantasma darwiniano de una desagradable evolución prehistórica. El asedio que la civilización ejerce sobre nuestro propio pasado evolutivo está magníficamente ejemplificado en la escena final, cuando los aviones acribillan a balazos al mono prehistórico que todos llevamos dentro. Este es, en general, el tema que ya habían tratado Poe (The Murders in the Rue Morgue, 1841) y Stevenson (Strange Case of Dr. Jekyll and Mr. Hyde, 1886). Durante la Segunda Guerra Mundial, Boris Karloff protagonizó un film de temática similar (El gorila, The Ape, William Nigh, 1940), en donde un antropoide aterroriza a todo un pueblo. También Béla Lugosi hace de hombre-mono en (The ape man, William Beaudine, 1943). No es casualidad que dos de los grandes popes del cine de terror protagonicen estos films de monos asesinos. Existe pues un cine de terror prehistórico, basado en la imagen ancestral de nuestro pasado evolutivo (The neandertal man, Ewald André Dupont, 1953). El tema del mono que rapta a una bella mujer, tiene siempre cierto carácter erótico (Link, Richard Franklin, 1986) o demoníaco (Atracción diabólica, Monkey Shines, Geroge A. Romero, 1988) ${ }^{3}$. Incluso en el cine de cienciaficción espacial, los planetas prehistóricos tienen un inconfundible erotismo femenino (Mujeres del planeta prehistórico, Women of the prehistoric planet, Arthur C. Pierce, 1966; Viaje a planeta de las mujeres prehistóricas, Voyage to the planet of prehistoric women, Peter Bogdanovich, 1968; Voyage prehistoric planet, Curtis Harrington, 1966) ${ }^{4}$. Pero la imagen del mono violador o asesino convivió a partir de los años sesenta con otra mucho más afable ${ }^{5}$, gracias a la labor de famosas investigadoras como Goodall (Miss Goodall and the Wild Chimpanzees, National Geographic, 1965). En películas de corte fantástico como El planeta de los simios (Planet of the Apes, Franklin J. Schaffner, 1968) y en sus numerosas versiones, la violencia no reside en nuestro doble simiesco (Mr. Hyde), sino en nuestra parte humana civilizada. Es muy curioso que en la última parte del serial realizado hasta la fecha (La guerra del planeta de los simios, War for the Planet of the Apes, Matt Reeves, 2017), nos vinculemos más con los personajes simios que con los humanos. Es más, estos supervivientes simios representan en realidad una nueva humanidad, frente a los viejos humanos que se exterminan en una fatal guerra fratricida. En esta línea, existen también ciertas películas de ciencia-ficción que están influenciadas por una interesante literatura de Wells (El tiempo en sus manos, The time machine, George Pal, 1960) a Clarke (2001, una odisea espacial, 2001, A Space Oddissey, Stanley Kubrick, 1968). En la secuencia inicial de 2001, se hace alusión a las ideas difundidas por Ardrey (1961) sobre el australopiteco asesino. Las novelas de ciencia-ficción, que tanto gustaban al gran prehistoriador François Bordes (1959), aluden en muchas ocasiones a la Prehistoria (Jameson, 2009).

3 Romero supo darle la vuelta a este tema, en su film es una hembra de chimpancé la que se siente atraída por un hombre.

4 Ambas son versiones de una película rusa que no presenta el mismo erotismo sexista (El planeta de las tormentas, Planeta Bur, Pavel Klushantsev, 1962).

5 Lo cual no quiere decir que no se siguieran haciendo las primeras películas, por ejemplo en Un viaje alucinante al fondo de la mente, Altered States, Ken Russel, 1980, el viaje regresivo de un científico a su propio pasado evolutivo lo convierte momentáneamente en un agresivo homínido. 

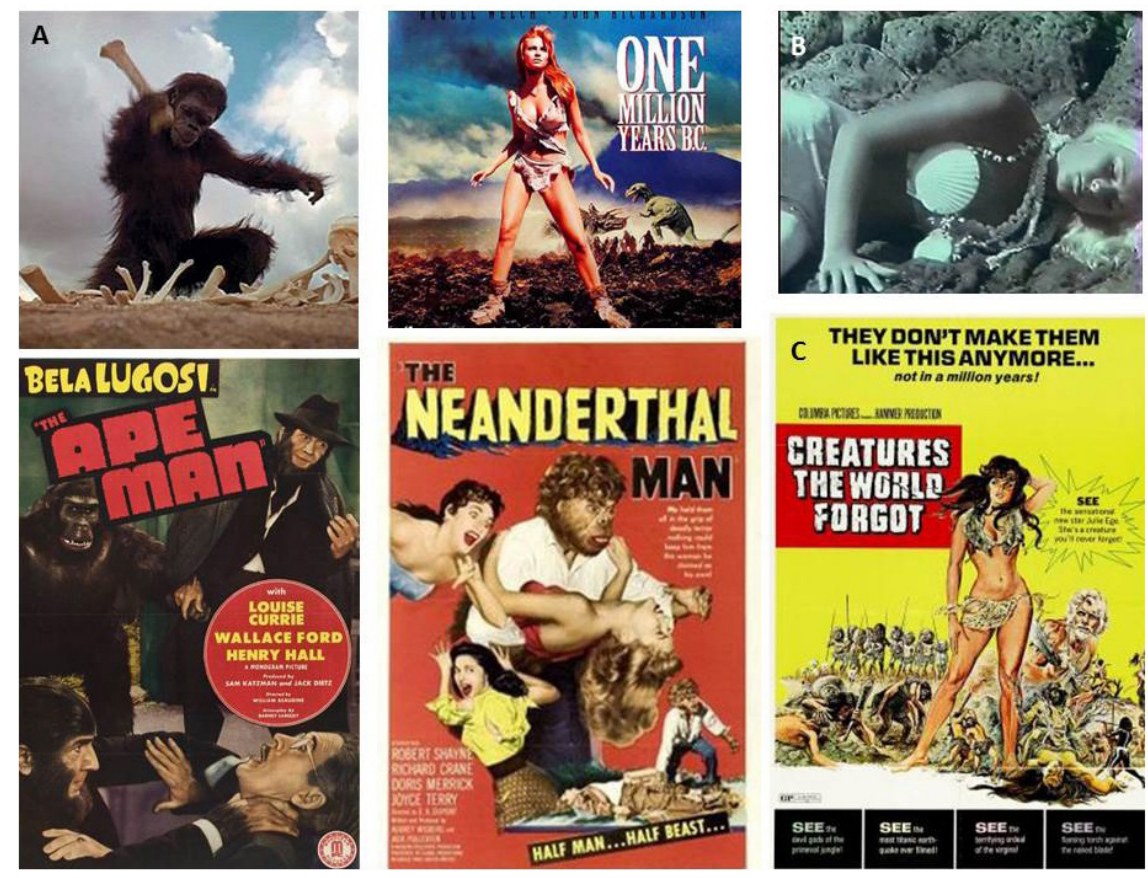

Figura 4: Algunos carteles de las películas mencionadas. A) Australopiteco que descubre la primera arma para matar (2001, una odisea espacial, 2001, A Space Oddissey, Stanley Kubrick, 1968). B) Venusianas presentadas como sirenas (Viaje a planeta de las mujeres prehistóricas, Voyage to the planet of prehistoric women, Peter Bogdanovich, 1968). C) El texto del cartel no tiene desperdicio: "Vean a la sensacional Julie Ege ¡Una criatura que jamás olvidará!”, “¡Vea a los diabólicos dioses de la primitiva jungla!”, "¡Vea el mayor terremoto jamás filmado!”, "¡Vea el terrorífico sacrificio de las vírgenes!”.

\subsection{Las ideas de la evolución en el cine actual}

La Prehistoria en el presente siglo alcanza una enorme diversidad de temas fílmicos, entre los que destaca la incursión de la evolución en el posthumanismo. Si con Griffith la evolución era la historia de un progreso (tecnológico, cultural y moral) en el cual la cultura occidental estaba en la cima, con las nuevas películas de superhéroes el significado de la evolución humana entra, subrepticiamente, en el campo de los posthumanismos. "Estamos asistiendo al comienzo de una nueva etapa de la evolución humana", dice la doctora Grey (X-Men, Bryan Signer, 2000). En el mismo film, antes de los títulos de crédito, una voz en off anuncia: "La mutación es la clave de nuestra evolución [...] Este proceso suele durar miles y miles de años. Pero, cada varios cientos de milenios, la evolución da un salto adelante". No es casual que la historia comience en un campo de concentración nazi, ya que está relacionando el sufrimiento con ese "salto adelante" de la evolución, en concreto con el dolor de un niño (Eric Lensherr) que será el futuro Magneto. Ambas ideas se relacionan, por ejemplo en Múltiple (Split, M. Night Shyamalan, 2016). La personalidad número 24 de un paciente con trastorno de identidad disociativo, y que alegóricamente vive en un zoo, evoluciona a través del sufrimiento. La bestia, como la llaman, "representa lo más elevado de la evolución humana" porque, según explican al final, "ella cree que el tiempo de la humanidad corriente se ha acabado". Esta bestia tiene una fuerza sobrenatural, como los super-villanos de los cómics. Los super-héroes de la Marvel también expresan el deseo de dejar atrás al anticuado homínido. Así lo advierte cínicamente Stark, más conocido como Iron Man: "Los seres humanos estamos biológicamente pasados de moda" (Vengadores: La era de Ultrón, Avengers: Age of Ultron, Joss Whedon, 2015). Si nuestro pasado orgánico-biológico está obsoleto, es porque las nuevas tecnologías hacen posible soñar con una nueva humanidad inmune a la descomposición 
orgánica. Este miedo a la carne, se observa también en las películas de zombis (De Groot, 2015) ${ }^{6}$. Pero si alguien refleja bien esa nueva superhumanidad creada por las nuevas tecnologías, son los personajes de la ciencia-ficción ideados por el cine. Es por esto que el origen de los nuevos superhéroes, como los de la Marvel, se encuentra siempre en las llamadas NBIC (nanotecnología, biotecnología, informática y ciencias cognitivas), que han dado pie a las ideas transhumanistas (Ferry, 2017). Dicho de otro modo, el éxito de los héroes de la Marvel se debe principalmente a que representan esta nueva mentalidad posthumana. Esta mentalidad está basada en una nueva forma de entender la evolución humana, que implica el rechazo de nuestro pasado orgánico-biológico y el advenimiento de una nueva realidad postbiológica (Koval, 2008). Mediante la manipulación genética, las leyes de la biología se pueden transgredir y la selección natural convertirse en artificial (Gattaca, Andrew Niccol, 1997). Se pueden resucitar especies extintas (Parque Jurásico, Jurassic Park, Steven Spielberg, 1993), pero también crear nuevas especies que jamás existieron (Jurassic World, Colin Trevorrow, 2015).

La evolución ya no es solo orgánica, sino que implica también a las máquinas (Haraway, 1995), es decir, la transformación del cuerpo en máquina y del cerebro en ordenador. Por eso, el nuevo King Kong del mundo postmoderno se arrodilla ante la máquina: "Los habitantes más inteligentes del mundo futuro no serán hombres ni simios. Serán máquinas" (Kong, la isla calavera, Kong: Skull Island, Jordan Vogt-Robert, 2017). También en el film Lucy (Luc Besson, 2014), se relaciona el pasado evolutivo con el futuro interactivo, pues al alcanzar el $100 \%$ de su potencial cognitivo, la protagonista (que se llama igual que el famoso australopiteco) se introduce en el mundo informático. En el imaginario fílmico, la parte homínida del ser humano ha evolucionado, por decirlo de alguna manera, del mono al hombre y del hombre a la máquina.

\section{Historia de los géneros}

Como ha sido señalado anteriormente, el primer género que recrea la Prehistoria en el cine es el cómico. La Prehistoria empezó en el cine a través de una adaptación de los chistes gráficos de Reed. Esta tradición ha continuado siempre, tanto en los cómics como en el cine, y ha perdurado sobre todo gracias a la influencia de la serie televisiva de Los Picapiedra en los años sesenta. En la actualidad, las películas cómicas sobre la Prehistoria son pequeñas producciones de escasa calidad en comparación con las originales. No obstante, la comedia es el segundo género más numeroso de producciones cinematográficas (Figura 5). Si le sumamos el de la animación, con el que está relacionado por su carácter lúdico, sumaría 36 casos, uno menos que el género fantástico.

Las películas de Griffith son el primer intento por hacer metrajes de larga duración, pues forman entre las dos una sola (Marzal, 1998). Además Griffith inventa formulas narrativas que luego se repetirán, como la figura del narrador de la historia que veremos en la primera versión de Hace un millón de años (1939). Este film señala el camino, ya iniciado por Griffith, de tramas que se decantarán por el género de aventura. En realidad, son también romances en los que cobrarán cada vez más protagonismo los dinosaurios y las catástrofes naturales. Estos romances con dinosaurios volverán a producirse en las décadas de los sesenta (Maciste contra los monstruos, 1962 y Hace un millón de años, 1966) y setenta (Cuando los dinosaurios dominaban la tierra, 1970 y Criaturas olvidadas del mundo, 1971), con relativo éxito.

Las tramas de Griffith y el cine posterior de aventuras, también acabaron influyendo sobre el

6 Incluso a veces los zombis parecen una especie de homínidos fallidos, pues en cierta medida expresan el fracaso de la evolución orgánica, porque viven después de la muerte pero de forma degradada y en eterna descomposición. No nacen, resucitan y salvo casos excepcionales (Las noches eróticas de los muertos vivientes, Le notti erotiche dei morti viventi, Joe D’Amato, 1980) no se reproducen. Son, en ese sentido, una anti-especie porque su sistema de reproducción está ligado al ser humano vivo al que comen. Los zombis son en unas ocasiones una alegoría de la extinción del cuerpo humano (Fernández, 2011) y en otras una regresión prehistórica. 
cine histórico. Si somos rigurosos, no podemos hablar más que de unas pocas películas históricas sobre la Prehistoria (Villaverde, 2012). Todas ellas se originan en los años ochenta, a tenor de las sagas literarias de Rosny (en concreto La guerre du feu, 1911) y Auel (en concreto, The clan of the Cave Bear, 1980). En el presente siglo el gusto por el realismo de las imágenes lleva a muchos directores a documentarse en busca de un mayor verismo visual. Este acercamiento a la Prehistoria no se ha producido tanto por una concienciación didáctica, sino por ese "efecto de lo real" -en este caso visual-, que anunciaba Barthes (1968). Los films buscan el verismo de las imágenes que se han instalado como prehistóricas en el imaginario colectivo. Ejemplos como Alpha (2018), que recuperan el género, lo hacen pareciéndose más a películas de supervivencia como Renacido (The Revenant, Alejandro González Iñárritu, 2015), que a sus precedentes. El cine prehistórico está siempre sometido a la moda, a los requisitos de la imagen, hoy hiperrealista, de lo que consideramos real. La Prehistoria se moldea y se adapta al género cinematográfico y a la época. Esto se observa sobre todo en las películas de ciencia-ficción. Si en los años sesenta la Prehistoria se adecúa a los viajes espaciales, en las películas actuales de superhéroes se ajusta a los avances en ingeniería genética y robótica. Quién crea que estas películas nada tienen que ver con la Prehistoria se equivoca profundamente. Es difícil comprender lo que pasa a nuestro alrededor sin tener en cuenta precisamente este tipo de películas. Estos films nos permiten comprender un poco cómo se han proyectado las ideas evolutivas en la imaginación actual. Nos enfrentamos a un cambio de significado importante en la manera de entender la evolución humana.

El género fantástico presenta un variado elenco de utopías, distopías, viajes a planetas prehistóricos o lugares erótico-primitivos. Pero si para la ciencia-ficción la Prehistoria es sobre todo un lugar en el que ubicar sus ensoñaciones, para el cine de terror es sobre todo una persona o un ser, a menudo monstruoso, en el que encarnar sus miedos. El cine prehistórico de terror está compuesto principalmente por las películas sobre homínidos o en las que aparecen, de una u otra forma, nuestros antepasados primates. Son sin duda el reflejo de nuestras propias pasiones, que en forma de sexo o violencia simbolizan, como se dice vulgarmente, el animal que llevamos dentro. Son, como bien explicó Gubern (2002), máscaras de la ficción bajo las que se ocultan los miedos del mundo civilizado por retornar al estado de barbarie primitiva (Losilla, 1997, p. 36). El género fantástico es el hasta la fecha más producido por el cine, aunque también el más variado en cuanto a subgéneros (aventuras, ciencia-ficción y terror).

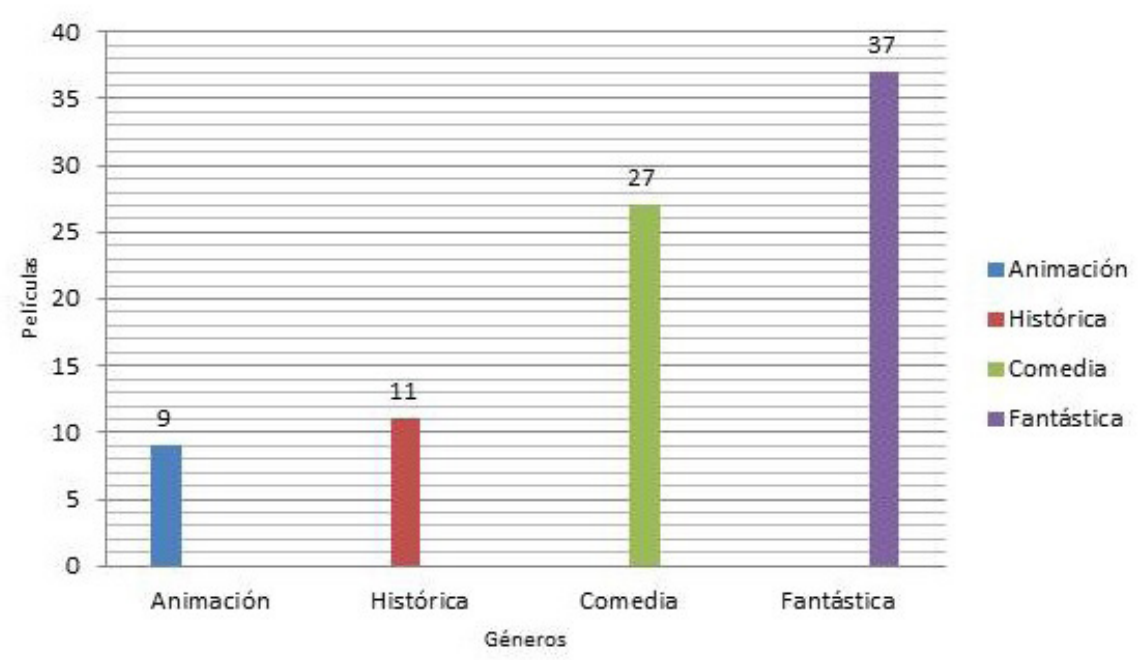

Figura 5: Cómputo total de los géneros de los materiales recogidos en el presente trabajo. 


\subsection{Cronología de los géneros}

El análisis de los géneros de nuestro corpus de películas por décadas ofrece resultados interesantes. Es llamativa la ausencia del género fantástico durante la primera década, en la que solo contabilizamos un caso (The cave girl, Joseph Franz, 1921) basado en novela homónima de Burroughs (1913). Pero, a partir de la siguiente, el progresivo aumento de las películas fantásticas va a la par que el de la ausencia del resto de géneros como la comedia, el cine histórico o las películas de animación. Esto es así hasta bien entrados los años sesenta y setenta cuando las comedias empiezan a resurgir y a paliar un poco ese monopolio del género fantástico (Figura 6). Son comedias italianas de relativo gusto, reflejo del éxito de la serie televisiva Los Picapiedra, verdadero revulsivo de este género durante los sesenta y setenta (Horral, 2018). El género fantástico empieza a decaer a mediados de los años setenta, cediendo su reinado a las producciones de carácter histórico y las comedias desde los años ochenta hasta hoy. Además, cabe señalar que dentro de este género, conviven varios subgéros que parecen tener una evolución propia. El subgénero de las aventuras es el más antiguo y estable y se desarrolla sobre todo después de la Segunda Guerra Mundial, mientras que la ciencia-ficción tiene un gran auge durante la década de los sesenta y el periodo de la Guerra Fría. Pero el cine de ciencia-ficción actual ha cambiado bastante con respecto al de esos años, pues a partir de los años noventa sobre todo empieza a perfilarse el tema de la evolución humana en torno a las nuevas tecnologías. Mención aparte merece el género de terror, que nació en Estados Unidos durante la depresión de los años veinte y en los albores de la Segunda Guerra Mundial, para prácticamente desaparecer en la actualidad, aunque quizás el terror prehistórico actual, que hemos medido solo en relación con los homínidos, se encuentre transfigurado en el talante primitivo de las humanidades que viven al margen de la civilización, ya sean comunidades rurales de la América profunda (La Matanza de Texas, The Texas Chain Saw Massacre Tobe Hooper, 1974; Bone Tomahawk, S. Craig Zahler, 2015) o de la selva amazónica (Holocausto caníbal, Cannibal Holocaust, Ruggero Deodato, 1980; Infierno verde, The Green Inferno, Eli Roth, 2013). Incluso los apocalipsis que asolan con frecuencia las pantallas con dinosaurios o sin ellos, son presentados a veces como un retorno a la Prehistoria, porque "la Prehistoria sigue siendo para el cine el lugar de la barbarie por excelencia" (Losilla, 1987, p. 38). Aquí la variedad y mezcolanza del cine de terror primitivo se nos escapa de las manos. Baste con recordar que una de las bases del cine de terror es la trasfiguración de la idea de lo primitivo como prehistórico, una idea que casi siempre encarnan culturas ajenas a la del hombre blanco occidental.

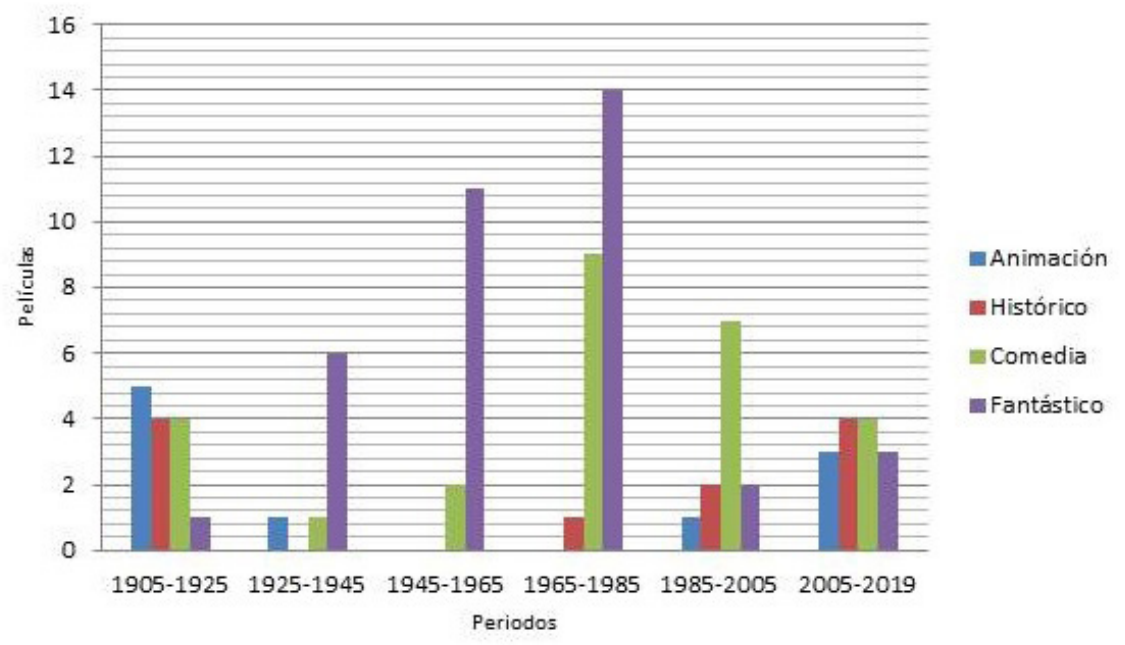

Figura 6: Cronología de los géneros de los films seleccionados. 


\subsection{Referentes literarios e icónicos de los géneros}

En el cine prehistórico hay referencias variadas, ideológicas, icónicas y narrativas. Son referencias cruzadas, es decir, se combinan dependiendo de los géneros y en menor medida de la época. Es interesante insistir, aunque sean bien conocidas, en las raíces de estas influencias. Por ejemplo, entre las literarias destaca Verne (Vojage au centre de la Terre, 1864) y Doyle (The Lost Word, 1912) para los films de ciencia-ficción. Para los films de homínidos de terror cabe mencionar a Poe (The Murders in the Rue Morgue, 1841) y a Stevenson (Strange Case of Dr Jekyll and Mr Hyde, 1886). Más tarde, el mono asesino se convierte en neandertal en los relatos de $\mathrm{H}$. G. Wells (A Story of the Stone Age, 1897 o The Grisly Folk, 1921), que influyó en autores como R. E. Howard (Spear and Fang, 1925). En los films de aventuras, a menudo ambientadas en selvas, destaca E. R. Burroughs, en concreto las series de Tarzán (Tarzan of the Apes, 1912) y Pellucidar (At the Earth ss Core, 1914). Esta última tiene una versión cinematográfica del mismo título, dirigida por Connor en 1976, que no hemos podido ver. La principal influencia de las comedias prehistóricas son las tiras cómicas de Reed (Mr. Punch's Prehistoric Peeps, 1894) u Opper (Our Antediluvian Ancestors, 1901). La cantidad de imágenes que el cine ha imitado de las tiras cómicas es innumerable, por ejemplo la del hombre subido a un dinosaurio domesticado o la del dinosaurio tragón. De hecho, los cómics han popularizado uno de los iconos visuales más perdurables en toda la historia del cine prehistórico. Nos referimos al hombre con maza y pieles difundido por las comedias y los dibujos animados hasta los presentes días.

La lucha de los machos por las hembras es uno de los primeros temas que los films de ambientación prehistórica adaptan de las tesis de Darwin. En este sentido, un precedente pictórico que refleja las tesis darwinianas lo encontramos en el cuadro de Kupka, Antropoides, 1902 (Figura 7 C). Se puede observar que la homínida en cuestión lleva unas flores, como en R.F.D. 10000 BC, 1916; Elefantes voladores, 1927 y Las tres edades, 1923 (Figura 7 D).

Entre las múltiples referencias icónicas del cine, podemos también destacar los dibujos de Bayard. Por ejemplo, el titulado "los primeros combates entre los hombres de la Edad de Piedra" en el libro, de enorme éxito divulgativo, El Hombre primitivo (Figuier y Zimmermann, 1871, lám. 135). Esta escena en la que se arrojan piedras, es semejante a la escena final de Las tres edades de Keaton. Otra influencia clara son los dibujos de Burian (Augusta y Burian, 1962) en el film de Zeman (Viaje a la Prehistoria, 1954), asesorado por el propio Augusta. También cabe mencionar, la estatua de Frémiet ya aludida, que ha tenido una enorme influencia en la imaginación de los gorilas asesinos $u$ hombres-mono violentos (Figura $7 \mathrm{~A}$ ). Y es que la Prehistoria antes que escribirse, se ilustró (Lagardère, 1990; Moser, 1998; Ruiz, 2016). Los cómics, las ilustraciones, las pinturas, han motivado numerosas recreaciones cinematográficas hasta un punto aún no investigado del todo. Es más, estas imágenes siguen inspirando todavía hoy a los directores de cine. Por ejemplo, "La persecución de los caballos de la roca de Solutré" dibujada a partir de un croquis de Arcelin (Roussot, 2003, p. 80, fig. 4), parece haber inspirado la escena de la caída de los bisontes en Alpha (2018). Igualmente en esta misma película, los cazadores agachados y camuflados con pieles, parecen evocar la ilustración de Catlin "la caza enmascarada del bisonte" (Hurel, 2003, p. 103, fig. 2). El mundo de la Prehistoria es un mundo de imágenes, más que saber, queremos ver.

Los referentes icónicos se renuevan en base a las nuevas tecnologías y las teorías científicas. La colaboración entre científicos y artistas es hoy en día fundamental para lograr ese efecto visual de verismo prehistórico. 

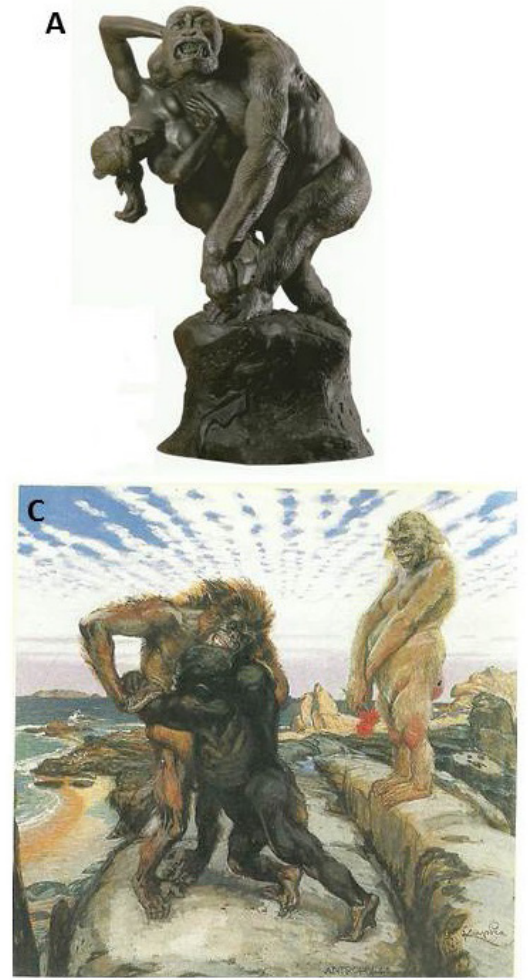

B
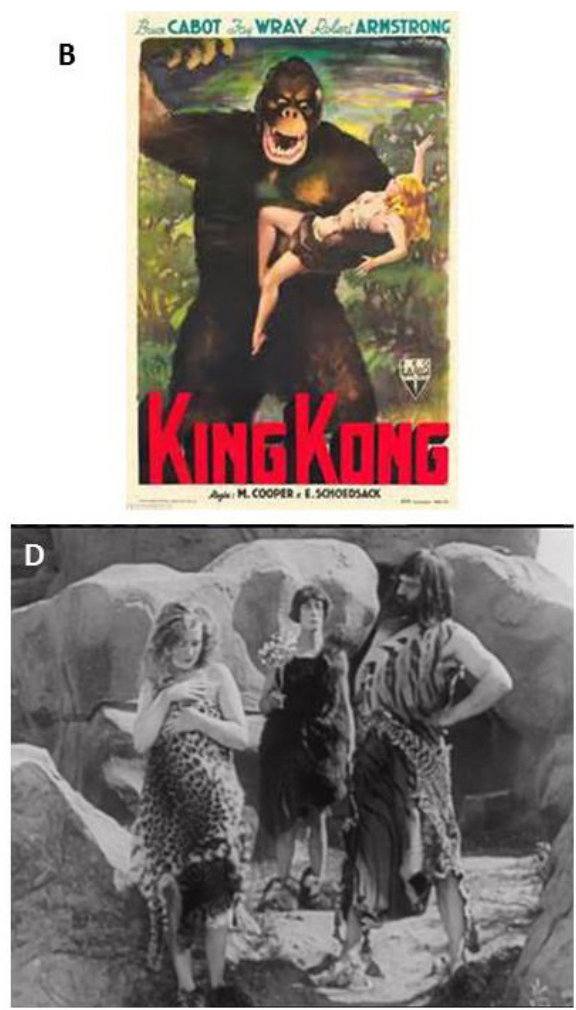

Figura 7: A) "Gorila raptando a una mujer" de Emmanuel Frémiet 1887 (Ducros y Ducros, 2000, 190, fig. 1).

B) Cartel de King Kong. C) Antropoides de Frantižek Kupka 1902 (Dagen, 2003, 36, fig. 3). D) Buster Keaton con flores en la mano frente a su competidor por la chica en Las tres edades (The Three Ages, Buster

Keaton y Edward Cline, 1923).

\section{Contenidos}

El análisis de los contenidos ofrece una diversidad que excede los parámetros expuestos en el presente trabajo. Los contenidos, es decir los temas que abordan las películas prehistóricas dependen en gran medida del género. No obstante, es el contenido de estos films donde se aprecia un mayor número concomitancias entre los diversos géneros. Una lista del variado temario al que nos enfrentamos sería inabarcable; sin embargo todo el variado mundo prehistórico cinematográfico puede estudiarse, reduciéndose mucho, en base a la imagen del hombre prehistórico (que encarna casi siempre la violencia) y la de la mujer prehistórica (que encarna casi siempre el sexo).

\subsection{Hombres}

Los hombres han de pelear contra otros por las mujeres, este es el hilo conductor de la trama de numerosas películas cómicas, fantásticas e incluso históricas. En la lucha masculina se enfrenta la fuerza contra el ingenio, donde gana siempre el ingenio. Es así ya desde los dramas de Griffith, que con el invento del arco consigue recuperar a la chica raptada por unos cavernícolas (La vida del hombre primitivo, 1914) o las comedias de Charlot y Keaton, que con sus ingeniosas bromas consiguen a la chica pretendida por un hombre de imponente aspecto físico. Esta idea, en el fondo, proviene de las tesis de Darwin sobre la competición sexual, pues según él, los ancestros semi-humanos masculinos y los salvajes habían luchado durante generaciones por la posesión de las mujeres (Vallin, 2000). Las películas de corte realista y sobre todo las comedias han explotado mucho esta idea, que también está presente de forma subrepticia en el cine fantástico, en la imagen 
del simio violador que antes mencionábamos. Las películas de terror explotaron el miedo a que la naturaleza prehistórica de nuestro ser retornara en el presente de mil formas diferentes. Una de las más llamativas es la del hombre-mono agresivo, auténtico precedente imaginario de las teorías sobre la violencia que popularizará años después Ardrey (1961). Ese salvaje que llevamos dentro fue visto como una herencia o un atavismo del pasado en el presente. De esta manera, Jack London criticaba la violencia de género, comparando a los maltratadores de su época con personajes homínidos como Ojo Bermejo, que en su novela Before Adam (1906-1907), agarra del pelo a las mujeres. Aquí aparece un estereotipo que el cine cómico difundirá hasta la saciedad. Nos referimos a la clásica imagen del hombre golpeando con el garrote a una mujer para llevársela cogida del pelo a la caverna (Las tres edades, 1923; La loca historia del mundo, 1981). Algo que las comedias no tardaron en invertir, mostrando a mujeres enormes que no se dejan arrastrar del pelo (Las tres edades, 1923) y acaban golpeando a hombres enclenques (Figura $1 \mathrm{D}$ ).

Pero a partir de los años cuarenta, el cine de aventuras crea un protagonista masculino dentro de un contexto épico (Hace un millón de años, 1939). Se trata de personajes a menudo musculosos como Victor Mature que, como si fuesen el mismísimo Hércules, se dedican a librar de monstruos (dinosaurios) la tierra. Son héroes fundacionales, exiliados de su tribu como Moisés, guerreros que conducen a su pueblo a la civilización, como Caín. Y claro está, tienen algo del primer Adán con su primera Eva. Se mezclan los mitos con un hibridismo sorprendentemente patriarcal. Los héroes prehistóricos del cine de aventuras representan siempre la fuerza y se relacionan simbólicamente con el sol. El ejemplo más claro de este culto masculino es Maciste, cuya exhibición corporal (con el cuerpo embadurnado de aceite) es comparable a la de las mujeres prehistóricas (Maciste contra los monstruos, 1962). Los héroes masculinos son los protagonistas de todas estas historias épicas y, salvo contadas excepciones (El clan del oso cavernario, 1986; Ao, le dernier neandertal, 2010), los verdaderos constructores de la civilización humana.

\subsection{Mujeres}

Las mujeres prehistóricas representan siempre el sexo y se relacionan simbólicamente con la luna. El papel de las mujeres prehistóricas en los primeros años del cine, hasta bien entrada la década de los sesenta, es ultraconservador. Aparecen casi siempre en la caverna, a veces incluso barriendo la casa (Prehistoric Poultry, 1916) y esto es así incluso en la famosa serie de Los Picapiedra. Este rol refleja la situación de las mujeres de la época como inmutable en el tiempo, como si fueran amas de casa desde siempre. Se puede argumentar que existen dos estereotipos de mujeres prehistóricas: la mujer buena (a menudo rubia, cariñosa y servicial) y la mujer mala (a menudo morena, guerrera y lasciva). Pero aún es peor cuando se trata de recrear el papel de las mujeres prehistóricas, pues aparecen como meros objetos sexuales. En numerosas ocasiones las mujeres son raptadas por hombres, homínidos o gorilas. El rapto de las mujeres y su posterior rescate es una de las subtramas más comunes de este tipo de cine. También hay mujeres selváticas que raptan a hombres, pero luego son convertidas por sus prisioneros en dulces esposas (Mujeres prehistóricas, 1950). Las sociedades de mujeres que viven sin hombres o son domesticadas por el hombre o bien son aberraciones monstruosas que aluden a mitos como el de las sirenas (Viaje al planeta de las mujeres prehistóricas, 1966) o se relacionan con las Amazonas (Mujeres prehistóricas, 1950). En los años setenta se desata el erotismo femenino. Las mujeres prehistóricas se convierten en símbolos sexuales. Raquel Welch, Julie Ege, Victoria Vetri, Martine Beswich o Mamie Van Doren, aparecen para ser vistas, ligeras de ropa, por espectadores masculinos. Este erotismo adquiere una dimensión geográfica en las películas de ciencia-ficción, pues todo mundo inexplorado en donde los hombres penetran, ya sea una selva virgen o un planeta desconocido, adquiere un significado femenino. No es casualidad que los planetas prehistóricos visitados por los exploradores espaciales masculinos se llamen Venus (Viaje al planeta prehistórico, 1965; Viaje al planeta de las mujeres prehistóricas, 1968).

Los cambios en la Prehistoria aparecen en los años 80 con la irrupción de las teorías feministas

Panta Rei (2019), 9 - 35 
y se aprecian sobre todo en las películas históricas (El clan del oso cavernario, 1986). Films como Altamira de Hudson (2016) o Ao, le dernier neandertal (2012), aluden a las mujeres como creadoras del arte paleolítico. El género femenino encuentra una liberación en estos personajes que mandan al traste muchos de los postulados tradicionales que han situado al hombre como el eje fundamental de la civilización y el arte. En lo que respecta a las películas de ciencia-ficción actuales que imaginan una evolución postbiológica, cabe señalar la existencia de heroínas mucho más independientes (Wonder Woman, Patty Jenkins, 2017). Las nuevas amazonas imaginadas por el cine en el presente siglo no se parecen en nada a las anteriores, pues son fruto de la mentalidad posthumanista. Se mueven dentro de un mundo apocalíptico en el que los seres humanos normales y corrientes, es decir, los regidos por las normas de la biología, están siempre en peligro. Las superheroínas encarnan una nueva humanidad que trasciende de los roles atribuidos desde antaño por la evolución biológica.

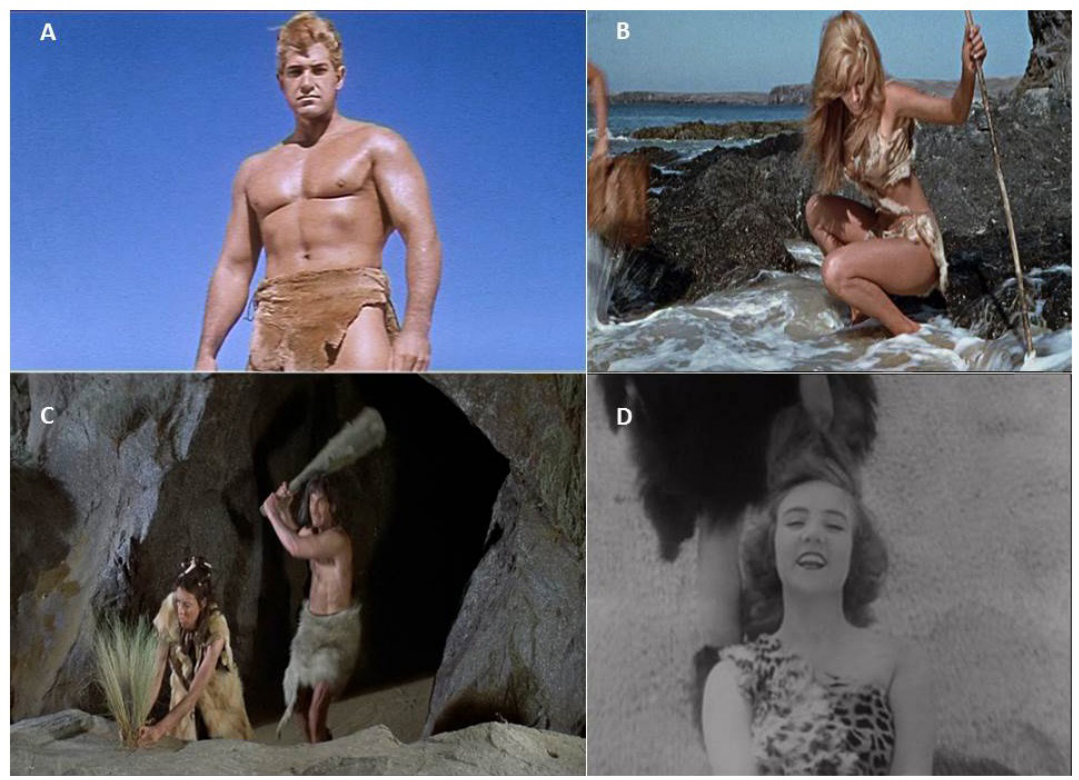

Figura 8: A) Reg Lewis luciendo sus músculos como hijo del sol (Maciste contra los monstruos, Maciste contro i mostri, Guido Malatesta, 1962). B) Raquel Welch en bikini, asociada a la espuma marina como Venus (Hace un millón de años, One Million B.C., Don Chaffey, 1966). C) Marido cavernícola (La loca historia del mundo, History of the World, Part 1, Mel Brooks, 1981). D) Buster Keaton arrastrando por el pelo a su chica (Las tres edades, The Three Ages, Buster Keaton y Edward Cline, 1923).

\subsection{Geografías perdidas}

Uno de los contenidos temáticos más irreales del cine prehistórico es el paisaje. A las primeras comedias del cine mudo, firmes herederas de las tiras cómicas, les interesaba destacar siempre la aridez del terreno. El paisaje rocoso, desnudo, en donde no hay prácticamente nada salvo unos personajes que se ven absurdamente rodeados de rocas, es el que observamos en las comedias de Keaton (Las tres edades, 1923) o el gordo y el flaco (Elefantes voladores, 1927). Este estereotipo de desierto, roca y cavernas se ha mantenido hasta nuestros días en otro género afín al cómico, como los dibujos animados (Los Croods: Una aventura prehistórica, 2013). Pero también el resto de géneros, incluso las películas realistas como las de Griffith (La génesis del hombre, 1912; La vida del hombre primitivo, 1914), han usado este paisaje de rocas y desierto. Este entorno rocoso -especie de metáfora visual de la Edad de Piedra-, es sin duda el prototipo fílmico más utilizado en la historia del cine prehistórico (Sanchis y Morales, 2012). Y es también una amalgama simbólica de mitos que evocan el desierto bíblico, la tierra caínica y, como no, el oeste norteamericano (Lombo y Alcolea, 2016). Estos entornos se combinan con otros en una misma película. Esto ocurre sobre todo en 
los films de aventuras donde la idea del viaje es fundamental para expresar las transformaciones anímicas que sufren los personajes. Así pues, podemos apreciar en un mismo film los más diversos e inverosímiles paisajes, dependiendo del momento o el carácter de la escena que se pretende representar. Por ejemplo, tras caer por un barranco, el héroe Tumak camina por el desierto hasta llegar a un paraíso edénico lleno de plantas exóticas, lagos azules y rubias en bikini (Hace un millón de años, 1966).

Sin embargo, las películas de aventuras de tipo tarzanesco tienen como prototipo el paisaje selvático (The cave girl, Joseph Franz, 1921, Mujeres prehistóricas, 1950; Las mujeres salvajes del Wongo, James L. Wolcott, 1958), a veces incluso una especie de edén donde viven los grupos de mujeres. De hecho, se las suele relacionar con el agua, las costas, los lagos o los ríos. En las versiones de corte terrorífico producidas por la Hammer, estos entornos adquieren un halo demoníaco (Mujeres prehistóricas, 1967), relacionando lo femenino con la luna. Los elementos del paisaje y las fuerzas de la naturaleza son trascendentales en el cine de ambientación prehistórica. En muchas de estas películas, las tormentas, los terremotos y las erupciones volcánicas tienen un claro componente providencial. Dicho sea claramente, son castigos divinos contra una comunidad que -dirigida por hombres o mujeres malvados, casi siempre de tez oscura- practica rituales paganos, sacrílegos y crueles. Un ejemplo claro de esto que decimos lo encontramos en el malvado jefe de los Drutas. El villano Fuan tiene un inconfundible aire fenicio y vive en una cueva donde hay un altar y un dintel decorado con imágenes de la luna y las estrellas que el culturista rubio Reg Lewis destroza. Cuando Fuan tiene capturado al forzudo, un repentino terremoto salva al héroe y aniquila parte de los Drutas (Maciste contra los monstruos, 1962).

Los acantilados tienen un papel fundamental en casi todas las historias. Suelen separar a los héroes de su tribu, y convertirlos en exiliados predestinados a fundar una nueva humanidad. Esto es lo que sucede en Alpha, en donde el joven Keda tras caerse por un acantilado, inicia un viaje de aprendizaje y retorno al hogar con la ayuda de una loba, cuya amistad, dice la voz en off, inaugurará una nueva etapa en la historia de la humanidad (Alpha, 2018). Las películas históricas son las únicas que han intentado reproducir un paisaje más o menos acorde con el periodo que se pretende representar; no obstante el paisaje depende siempre de la historia narrada o de la estética del momento. En la actualidad, algunas producciones cuentan con un largo elenco de artistas visuales que, gracias a los efectos especiales hechos por ordenador, pueden convertir el paisaje natural filmado en un auténtico decorado virtual. Esto sucede en películas como la mencionada Alpha, en donde las noches se nos muestran coloreadas en un tono azul y las pavesas de las hogueras y las luciérnagas se transforman en estrellas. Los paisajes virtuales, de estética hiperrealista de Alpha, nos ofrecen una simbología mucho más amena de la noche, la luna y las estrellas.

\section{Discusión}

La clasificación de las películas mediante géneros, presenta algunos inconvenientes, pues ni los géneros son categorías estables, ni la Prehistoria existe como género cinematográfico. Existen sin embargo, distintos tratamientos (cómicos, fantásticos, realistas...) de la Prehistoria en el cine. Aunque en los años sesenta y setenta, se observan tímidos intentos de crear una especie de prototipo de película prehistórica en base a ciertos elementos estándar, como los paisajes, los dinosaurios y las mujeres ligeras de ropa, en realidad eran películas de bikinis y dinosaurios, que durante aquel momento se convirtieron en un modelo de lo que tenía que ser una película prehistórica. Por lo demás, el resto de estereotipos son de carácter universal. Por ejemplo el vestido del hombre prehistórico, es prácticamente una marca comercial, como las sandalias romanas, el sombrero de Indiana Jones o el traje de James Bond.

El mismo problema nos lo encontramos al intentar clasificar las películas de terror a partir de los años cincuenta, pues, como afirma Altman (2000), los géneros se disfrazan, es decir, lo que en los años treinta era cine de terror en los años cincuenta empieza a llamarse ciencia-ficción. A este proceso de redefinición del género, el autor lo denomina "regenerificación" (Altman, 2000, p. 116). 
Esto es lo que se percibe en el caso de lo que más bien podrían llamarse películas de simios o de homínidos, cuya clasificación es fácilmente reconocible bajo el género de terror en las producciones de la Universal de los años treinta y cuarenta, pero que luego nos las encontramos camufladas en el género fantástico. De nuevo aquí los géneros intentan despistarnos, porque existe todo un cine de terror prehistórico oculto en los diversos géneros e incluso en las películas actuales que en apariencia nada tienen que ver con el periodo prehistórico. Cabe por lo tanto no solo incluir entre los monstruos a los simios (hombres-mono o monos-hombres), sino detectar la naturaleza prehistórica de todo ser monstruoso. Los géneros, por lo tanto, nos ayudan a ordenar y entender el material, pero dificultan la percepción de relaciones imprescindibles para el estudio de la Prehistoria en el cine. Otro caso parecido, nos lo ofrece el cine de aventuras, en donde se incluyen películas de tendencias dispares: unas tienden a la épica, otras a los romances o a las narraciones de viajes.

Así pues, es más que lícito preguntarse qué tipos de películas prehistóricas nos encontramos dentro de los géneros estipulados. Desde este punto de vista, podemos hablar de películas de homínidos, films de mujeres selváticas, del espacio sideral o de bikinis y dinosaurios. También existen films ambientados en el periodo prehistórico y en los que se viaja a la Prehistoria o se vive la Prehistoria desde el presente en forma de restos, atavismos, herencias a un pasado a veces siniestro. En esta amalgama enorme, los géneros se confunden y, alimentándose de fuentes diversas, crean distintas Prehistorias que el público conoce bien. Según el tipo de film que se le propone, el espectador está preparado para lo que se le ofrece. Realidad, fantasía, sueño, miedo..., dependen de la época y el género. El público de principios del siglo XX podía distinguir entre la comedia prehistórica de Charlot, los dramas prehistóricos (no exentos de ironía) de Griffith o los monstruos de O'Brien. Desde luego, resulta difícil incluir los films de Griffith entre los históricos, pero de alguna forma tenían una intención realista, sobre todo de expresar las teorías darwinianas, que lo asemejan a las tendencias historicistas de los años posteriores. El género histórico propuesto aquí, por lo tanto, puede incluir casos de talante realista y documentales actuales, como el de Herzog, que no pertenecen en realidad a ningún género. Muchas películas actuales son auténticos géneros híbridos (Lipovetski y Serroy, 2009). Esto se observa bien sobre todo en el fantástico, pues las películas de aventuras y las de ciencia-ficción se mezclan con las de terror. Cabe insistir en la pervivencia del cine de terror prehistórico en otro tipo de películas, pues es raro que haya desaparecido. Parece más bien que se ha transmutado en una diversa amalgama de films que tienen como base la idea del terror de lo primitivo, es decir, comunidades salvajes, zombis, monstruos y demás alegorías de primitivismo prehistórico.

Además, si somos severos en realidad existen muy pocas películas que podríamos calificar como históricas (Villaverde, 2012). Los géneros pueden confundirnos. Incluso una película de dibujos animados, como La edad del Hielo (2002) se acerca bastante a lo histórico. Lo que se observa en la actualidad es una "convergencia" como bien afirma Ruiz (2016) refiriéndose a los comics. Con ejemplos como Alpha (2018) podemos constatar que el mencionado acercamiento se produce también en el cine.

Ahora bien, en nuestra opinión, el cine prehistórico engloba distintos géneros, no solo el histórico. Además, para analizar la manera que tiene el cine de utilizar todo lo que concierne a la Prehistoria, hay que tener en cuenta películas que sin ser prehistóricas aluden a la Prehistoria de alguna otra forma. Cuando un personaje, sea cual sea, menciona la Prehistoria, se debe analizar el contexto y la causa de dicha mención. No se cita la Prehistoria por casualidad, incluso las películas de zombis aluden a la Prehistoria ${ }^{7}$ por alguna razón. Es posible que el cine de terror prehistórico se encuentre esparcido en pequeñas partículas irreconocibles de films diversos, como ya hemos advertido. La Prehistoria da miedo, encarna personajes salvajes o monstruos que atentan contra la civilización.

7 El doctor Logan explica que los zombis comen aunque no tienen estómago, porque obedecen a sus primitivos instintos ubicados en el núcleo del cerebro, el complejo R, "la parte de sustancia prehistórica que heredamos de los reptiles" (El día de los muertos, Day of the Dead, George A. Romero, 1985). 
Dicho todo lo cual, la historia del cine prehistórico es más importante y compleja de lo que se suele creer. Las relaciones entre la Prehistoria y cine son vitales para conocer el origen y entender un tema tan importante como el de la violencia. La idea de que nuestros antepasados eran violentos y hemos heredado esa violencia de manera innata, ha tenido una grandísima influencia en el cine. Esta es una idea que proviene de los trabajos sobre los australopitecos surafricanos de Dart (1953) que, difundido por Ardey (1961) y Lorenz (1966), tuvieron una importantísima trascendencia en el cine de los sesenta y setenta. De ahí sale la idea del australopiteco asesino de 2001, una odisea espacial (2001, A Space Oddissey, Stanley Kubrick, 1968) y todo un largo elenco de distopías de la violencia en mundos futuros (La carrera de la muerte del año 2000, Death Race, Paul Bartel, 1975) ${ }^{8}$ o en comunidades rurales (Perros de paja, Straw Dogs, Sam Peckinpach, 1971) $)^{9}$. Incluso se habla de un gen de la violencia, el MAO-A que explica la agresividad de los maorís de Nueva Zelanda (Guerreros de antaño, Once Were Warriors, Lee Tamahori, 1994). Todas estas películas no son prehistóricas, pero no se pueden entender sin conocer la bibliografía prehistórica, es decir, sin saber que el origen de tales teorías se encuentra en los trabajos de Dart y Ardrey sobre homínidos.

Para Drummond (1996), el cine fantástico funciona como una especie de mitología que define la identidad de lo humano. Efectivamente, si en un primer momento la identidad de lo humano se configuró en base a la idea de lo civilizado y en contra de la idea de lo primitivo, muchos films del presente siglo reconfiguran la identidad de lo humano en base a las nuevas tecnologías y en contra de todo lo orgánico. Por eso el paisaje prehistórico es siempre tan irreal, es la frontera que separa ambos mundos ideológicos, lo masculino de lo femenino, lo occidental de lo oriental, lo orgánico de lo inorgánico. La Prehistoria es un espacio simbólico, un desierto estéril que el hombre debe fecundar o, por el contrario, un lugar de exuberante fertilidad que el hombre debe dominar. Sin embargo, en el presente siglo la Prehistoria se encuentra en el fondo de todo paisaje apocalíptico, oponiéndose a la tecnología actual y a la reconstrucción de la nueva identidad humana. Por lo tanto, una nueva manera de entender la evolución está empezando a arraigarse en el imaginario fílmico del siglo XXI. El ser humano puede evolucionar, ya no siguiendo las leyes de la biología, sino las de la tecnología. Esto supone no solo el rechazo de nuestro pasado orgánico-biológico porque, como dijo el superhéroe Iron Man, está pasado de moda, sino también el advenimiento de una nueva idea de lo humano, que algunos autores llaman posthumanismo. Este posthumano, que se refleja sobre todo en el cine de superhéroes, es sin duda un superhombre y es concebido como el siguiente escalón de la evolución. Ni qué decir tiene que el nacimiento de la nueva humanidad implica la defunción de la antigua, o el fin del Homo sapiens (Harari, 2014). Ambos fenómenos, la extinción del Homo sapiens y el advenimiento de una nueva especie mutante o robótica, están relacionados, pues son causa y consecuencia el uno del otro. El supuesto perfeccionamiento humano implica erradicar la violencia porque se considera un residuo del pasado.

En resumen, hay tres ideas que han influido en las películas estudiadas: las teorías darwinistas, las hipótesis difundidas por Ardrey y el posthumanismo. Estas ideas influyen sobre todo en las historias narradas, las relaciones entre personajes y la simbología del paisaje. Los géneros se reconfiguran en torno a estas tendencias o más bien se adaptan a ellas, creando un nutrido grupo de subgéneros y variantes híbridas. Pero los géneros y sus variantes no mantienen relaciones estables, los mismos paisajes, por ejemplo, pueden aparecer en películas de géneros distintos. Los géneros, como bien dijo Altman (2000), son interfecundables, no tienen barreras infranqueables,

\footnotetext{
8 Antes de los títulos de crédito finales una voz en off revela la influencia ardreyana del film: "Así es el tema de la violencia. La técnica de la violencia se desarrolló por primera vez hace dos millones de años por el australopitecus, se fue desarrollando con los primates que no poseían capacidad de hablar, pero que, en todo caso, inventaron el tomahawk y se bombardearon unos a otros. Esta práctica contribuye al crecimiento del cerebro, otra arma de gran utilidad, sí, el asesinato se inventó incluso antes de que el hombre empezara a pensar, ahora por supuesto, se conoce al hombre como "animal racional".

9 El director norteamericano poseía un ejemplar del libro de Ardrey Territorial Imperative que le regaló el actor Strother Martin cuando termino el rodaje de Grupo salvaje (Navarro, 2013).
} 
solo algunas limitaciones. La Prehistoria en el cine es un universo fecundo que tiene una prodigiosa variedad de relaciones.

Tabla 2

Síntesis de los diversos tipos de películas, géneros, estereotipos e ideas dominantes del cine prehistórico

\begin{tabular}{|c|c|c|c|}
\hline Clasificación & Características & \multicolumn{2}{|l|}{ Exteriores } \\
\hline \multirow{9}{*}{$\begin{array}{l}\text { Géneros, subgé- } \\
\text { neros y variantes }\end{array}$} & Comedia & & \\
\hline & Animación & & \\
\hline & Historia & & \\
\hline & Cine fantástico & Aventura & Mujeres selváticas \\
\hline & & & Dinosaurios \\
\hline & & & Bikinis \\
\hline & & Terror & Homínidos asesinos \\
\hline & & Ciencia-ficción & Espacial \\
\hline & & & Post-humanismo \\
\hline Personajes & \multicolumn{3}{|c|}{$\begin{array}{l}\text { Adán, Eva, Caín, Moisés, Amazonas, Hércules, Sirenas, Tarzán, hombre sal- } \\
\text { vaje, mujer salvaje, hombre mono, mono hombre, bestia, dinosaurios, mons- } \\
\text { truos }\end{array}$} \\
\hline Exteriores & \multicolumn{3}{|c|}{$\begin{array}{l}\text { Desiertos, Edán, hiperreales, mundos perdidos, oeste americano, planetas de } \\
\text { mujeres, tierras malditas, terremotos, volcanes }\end{array}$} \\
\hline \multirow[t]{3}{*}{$\begin{array}{l}\text { Ideas dominan- } \\
\text { tes }\end{array}$} & Ideas darwinianas & \multicolumn{2}{|c|}{$\begin{array}{l}\text { Competición sexual - lucha por la superviven- } \\
\text { cia }\end{array}$} \\
\hline & Ideas ardreyanas & \multicolumn{2}{|c|}{ Violencia innata - australopiteco asesino } \\
\hline & Ideas posthumanistas & \multicolumn{2}{|c|}{ Fin del homo sapiens - superhumanidad } \\
\hline
\end{tabular}

Fuente: elaboración propia.

\section{Reflexiones finales}

El estudio de la Prehistoria en el cine mediante géneros nos ofrece cinco tipos de películas a estudiar: (1) los dibujos animados, (2) las comedias, (3) las películas históricas, (4) las fantásticas y (5) las que mencionan, usan o desarrollan conceptos e ideas propias de la Prehistoria.

La animación es el género más antiguo y tiene su continuidad hasta nuestros días; pero desde los cortos de animación stop motion a los largometrajes de la era digital, ha sufrido una enorme transformación estético-técnica. Sin embargo, las comedias, influidas por tiras cómicas de finales siglo XIX, han variado menos. Los chistes de Charlot, Keaton, Laurel y Hardy, basados en los golpes, las caídas y las peleas del llamado cine burlón o slapstick, perduran en el cine posterior, aunque en películas de carácter distinto. Este género es, en esencia, el más invariable de todos.

Por el contrario, el subgénero de terror, relacionado con el tema de los hombres-mono asesinos (influencia de las novelas de Poe y Stevenson), es el más efímero. Sin embargo, es muy posible que el cine de terror prehistórico se encuentre presente de otra forma en otro tipo de películas de épocas posteriores.

El género de aventuras, parece tener un comienzo en las novelas de Burroughs, en films de grupos de mujeres selváticas que tendrán una notable continuidad y ha ido desembocando también (gracias a obras como las Doyle y Verne) en viajes a mundos perdidos con dinosaurios. Las películas de bikinis con dinosaurios son sin duda las más populares e influyentes de este género, tienen su auge en los años sesenta y setenta. 
Las películas de ciencia-ficción por su parte son difíciles de definir. Algunas pueden considerarse de aventuras o de terror. Quizás, lo verdaderamente destacable de este subgénero sea su peculiar relación con la coyuntura científica. De esta manera, en la década de los sesenta destacan las películas de viajes espaciales y, en la década de los noventa, las películas que hablan de la evolución humana, la genética y la robótica.

El género histórico tiene quizás sus precedentes en las películas de talante realista de principios del siglo $X X$, pero se desarrolla en los años ochenta gracias al impulso de los seriales de Auel. A pesar de ser un género reciente, parece cobrar gran fuerza actualmente gracias a las recreaciones virtuales y a la estética hiperrealista que exige la credibilidad fílmica de este periodo.

El estudio de los géneros nos ayuda también a establecer una serie de tendencias generales en la historia del cine prehistórico. Estas preferencias se mezclan, hibridan, conviven, pero también se imponen en cada uno de los ciclos sobre otras. La primera tendencia es la del ciclo cómico (19051940) y estaría formado por las películas de animación y las cómicas, que inician la proyección de la Prehistoria en clave de humor y bajo una clara influencia de los tebeos de finales del siglo XIX. Este periodo es sobre todo humorístico, incluso las películas de talante realista tienen siempre un tono irónico, en relación casi siempre con las teorías de Darwin.

El segundo ciclo (1940-1970) estaría marcado por la incursión del género fantástico, iniciado por el cine de terror y por el cine de aventuras en las postrimerías de la Segunda Guerra Mundial. El primero será efímero (aunque puede que se halla diversificado en otros tipos de films), pero el segundo tendrá una larga prosperidad durante la Guerra Fría, en las películas de bikinis y dinosaurios. La ciencia-ficción, sobre todo la espacial, también se desarrolla en este momento con una larga perduración hasta nuestros días.

El tercer ciclo (1980-2019) señala surgimiento del cine histórico y la tendencia realista o hiperrealista de las imágenes. El tema del género fantástico ha cambiado, pues si en el pasado siglo la ficción se hacía eco, primero de la ciencia darwinista, segundo de las ciencias físicas (la Prehistoria como metáfora de la bomba atómica), en el presente siglo lo hace de las nuevas ciencias tecnológicas NBIC. Se trata de un cine que no es del todo prehistórico pero que menciona a la Prehistoria casi como un mantra de los peligros a los que nos puede conducir los excesos de la tecnología. Es el ciclo del fin del Homo sapiens y el inicio de los posthumanismos.

El contenido de estos films depende más de las épocas que de los géneros, es casi siempre coyuntura de los tiempos. Y es que la historia de la Prehistoria en el cine es, bajo nuestro punto de vista, mucho más que la mera clasificación por géneros de sus películas. Es la base de la credibilidad de muchas de las ficciones narrativas cinematográficas y el fundamento de las nuevas teorías sobre la evolución humana. La historia del cine prehistórico nos permite observar el cambio fundamental que se ha experimentado en la manera de concebir la evolución humana.

En el mundo del cine, la Prehistoria está más viva que nunca. Espejo de las numerosas ficciones que nos persiguen, la Prehistoria en el cine es un corazón que late con fuerza dentro del imaginario de cada uno de nosotros.

\section{Bibliografía}

Altman, R. (2000). Los géneros cinematográficos. Barcelona: Paidós.

Ardrey R. (1961). African Genesis. New York: Atheneum.

Augusta, J. y Burian, Z. (1962). Das buch von den mammuten. Czechoslovakia: Artia.

Ayán Vila, X. (2017). Hugh Hudson (director). Altamira. Nailos, 4, 292-296.

Azéma, M. (2011). La préhistoire du cinéma. Origines paléolithiques de la narration graphique et du cinématographe... Paris: Errance.

Barthes, R. (1968). L'Effet de Réel. Communications, 11, 84-89.

Carvajal, A., Hernando, C., Soto, M. M., y Tejerizo, C. (2011). El Síndrome de Indiana Jones. La imagen social del arqueólogo. Estrat Crític, 5, 38-49.

Blanco, A. (1993). Cinesaurios. Barcelona: Royal Books. 
Bordes, F. (1959). Science-fiction et préhistoire. Satélite, 16, 173-186.

Bourget, J-L. (1992). L'Histoire au cinema. Le passé retrouvé. Paris: Gallimard.

Dagen, P. (2003). Imágenes y leyendas de la Prehistoria. En Venus y Caín. Nacimiento y tribulaciones de la Prehistoria en el siglo XIX (pp. 16-43). Madrid: Ministerio de Educación, Cultura y Deporte.

Dart, R. (1953). The predatory transition from ape to man. International Anthropological and Linguistic Rewiew 1 (4), 201-218.

De Groot, J. (2015). Remaking History. The past in contemporary historical fictions. London: Routeledge.

Drummond, L. (1996). American Dreamtime. A Cultural Analysis of Popular Movies, and Their Implications for a Science of Humanity. Lanham: Rowman \& Littlefield Publishers.

Ducros, A. y Ducros, J. (2000). Du gorille à I'homme fossile: art et science. En A. Ducros, y J. Ducros. (eds.), L'homme préhistorique. Images et imaginaire (pp. 189-201). Paris: L'Harmattan.

Egea, A. y Arias, L. (2015). Russell Crowe el gladiador, Colón el descubridor y otros protagonistas de la historia: buceando en las narrativas históricas de jóvenes universitarios españoles, Clio. History and History Teaching, 41. Recuperado de http://clio.rediris.es/

Fernández Gonzalo, J. (2011). Filosofía zombi. Barcelona: Anagrama.

Fernández Martínez, V. (1991). La arqueología de la Imaginación: Notas sobre literatura y Prehistoria, Arqritica, 2, 3-6.

Ferry, L. (2017). La revolución transhumanista. Madrid: Alianza.

Figuier, M. M. L. y Zimmermann, W.F.A. (1871): El mundo antes de la creación del hombre. Origen del hombre. Problemas y maravillas de la Naturaleza. Tomo II. Barcelona. Montaner y Simon.

García-Escárzaga, A. (2013). Análisis científico de Ao, el último neandertal (J. Maleterre, 2010), Frame, 9, 37-66.

González Morales, M. (2018). Releyendo la Prehistoria. Los pintores (negros) de Altamira y otras historias. Madrid: La Huerta Grande.

Gubern, R. (2002). Máscaras de la ficción. Barcelona: Anagrama.

Harari, Y. N. (2014). De animales a dioses. Breve historia de la humanidad. Barcelona: Debate.

Haraway, D. J. (1995). Ciencia, cyborgs y mujeres. La reinvención de la naturaleza. Madrid: Cátedra.

Hernández Descalzo, P. (1997). Luces, cámara, jacción!: Arqueología, toma 1. Complutum, 8, 311334.

Horrall, A. (2018). Inventing the cave man: from Darwin to the Flintstones. Manchester: Manchester University Press.

Hurel, A. (2003). Hombres salvajes y hombres fósiles del escultor Constant Roux. En Venus y Caín. Nacimiento y tribulaciones de la Prehistoria en el siglo XIX (pp. 100-105). Madrid: Ministerio de Educación Cultura y Deporte.

Jameson, F. (2009). Arqueologías del futuro. El deseo llamado utopía y otras aproximaciones de ciencia ficción. Madrid: Akal.

Jardón, P., Pérez, C. y Soler, B. (2012). Prehistoria y cine. Valencia: Museu de Prehistòria de Valencia.

Kempen, B. (1994). Abenteuer in Gondwanaland und Neandertal: prähistorische Motive in der Literatur und anderen Medien. Meitingen: Corian-Verlag.

Klossner, M. (2006). Prehistoric Humans in Film and Television: 581 Dramas, Comedies and Documentaries. Jefferson London: Mc Farland \& Company.

Koval S. (2008). La condición poshumana. Camino de la integración hombre-máquina en el cine y en la ciencia. Buenos Aires: Cinema.

Lagardère, G. (1990). Peintres d'un monde disparu: la préhistoire vue par les artistes de la fin de $X I X^{e}$ siècle à nos jours. Solutré-Pouilly: Musée de Préhistoire de Solutré.

Lipovetski, G. y Serroy, J. (2009). La pantalla global. Cultura mediática y cine en la era hipermoderna. Barcelona: Anagrama.

Lombo, A. (2014). La cueva de los sueños olvidados de Herzog. ArkeoGazte, 4, 297-302.

Lombo, A. (2015). El arte paleolítico en El Carnicero de Chabrol. Panta Rei, Revista Digital de Ciencia 
y Didáctica de la Historia, 139-142. Recuperado de https://doi.org/10.6018/pantarei/2015/13. Lombo, A. y Alcolea, M. (2016). Hace un millón de años. Complutum, 27 (1), 219-222.

Lorenz, K. (1966). On Aggression. Londres: Methuen.

Losilla, C. (1997). La Prehistoria, los dinosaurios y otras criaturas feroces de Willis O'Brien a Steven Spielberg. Dirigido por... 259, 336-43.

Martín, I. (2006). La Prehistoria en el cine. Panta Rei, Revista Digital de Ciencia y Didáctica de la Historia, 25-29. Recuperado de https://doi.org/10.6018/pantarei/2006/2.

Marzal, J. J. (1998). David Wark Griffith. Madrid: Cátedra.

Moser, S. (1998). Ancestral Images. The Iconography of Human Origins. Ithaca: Cornell University Press.

Navarro, J.A. (2013). Perros de paja. Mundos opuestos. Dirigido por ..., 439, 53-55.

Richard, N. (2008). Inventer la préhistoire. Les débuts de l'archéologie préhistorique en France. Paris: Viuibert Adapt

Rojano Simón, M. (2016). De las cuevas al cine: la Prehistoria en el cine y la televisión Metakinema, 19. Recuperado de http://www.metakinema.es/metakineman19s5a1 Prehistoria Cine Television Marta Rojano Simon.html.

Roussot, A. (2003). ¿Ario o lapón? En Venus y Caín. Nacimiento y tribulaciones de la Prehistoria en el siglo XIX (pp. 76-83). Madrid: Ministerio de Educación, Cultura y Deporte.

Ruiz, G. (2016). Ilustración prehistórica y tebeo de Prehistoria: ¿caminos divergentes o convergentes? En H. Bonet, H. y Moreno, A. (eds.), Prehistoria y cómic (pp. 59-86). Valencia: Museo de Prehistoria de Valencia. Diputación de Valencia.

Ruiz, G. y Castaño, A. M. (2008). Arqueologia e cinema, uma história em comum. Revista Arqueologia Pública, 3, 19-33.

Sanchis, A. y Morales, J. V. (2012). Paisaje y fauna: de la arqueología a la pantalla. En P. Jardón, C. Pérez, y B. Soler. (eds.), Prehistoria y cine (pp. 56-68). Valencia: Museu de Prehistòria de València.

Semonsut, P. (2013). Le passé du fantasme. La représentation de la préhistoire en France dans la seconde moitié $d u X X X^{e}$ siècle. Paris: Errance.

Soler, B. (2016). ¡Gracias Lucy! En H. Bonet y A. Moreno (eds.), Prehistoria y cómic (pp. 167-191). Valencia: Museo de Prehistoria de Valencia. Diputación de Valencia.

Tejerizo García, C. (2011). Arqueología y cine: distorsiones de una ciencia y una profesión. El futuro del Pasado, 2, 389-406.

Vallin L. (2000). Agressivité et violence de l'homme préhistorique dans ses représentations modernes. En A. Ducros y J. Ducros (eds.), L'homme préhistorique. Images et imaginaire (pp. 173-188). Paris: L'Harmattan.

Villaverde, V. (2012). El destino de los neandertales: cine y evolución humana. En P. Jardón, C. Pérez y B. Soler. (eds.), Prehistoria y cine (pp. 39-68). Valencia: Museu de Prehistòria de Valencia.

Vogel, J., Randau, F. y Zink, A. (2017). Der Mann aus dem Eis. Ditzingen: Reclam. 



\section{Panta Rei}

PANTA REI es una revista digital de investigación orientada a la Historia y otras ciencias afines. Su principal objetivo es la transmisión del conocimiento científico, dando una oportunidad también a los jóvenes investigadores que quieren abrirse camino en el estudio de las ciencias humanas y sociales. Se compone de estudios originales relacionados con la disciplina histórica así como su didáctica y difusión. Las diferentes secciones que componen la revista son: artículos de investigación, entrevistas a profesionales, recensiones de monografías de actualidad y crónicas de congresos o eventos científicos relevantes.

Todos los artículos publicados son objeto de un proceso de revisión a cargo de un mínimo de dos evaluadores, que se consideran expertos en el ámbito temático del artículo propuesto. Nuestro deseo es poder ofrecer unos contenidos rigurosos, de calidad y de interés.

EI CEPOAT (Centro de Estudios del Próximo Oriente y la Antigüedad Tardía de la Universidad de Murcia) es la institución encargada de la coordinación y gestión de la revista, desde donde anualmente se lanzará la convocatoria para aquellos que estén interesados en publicar sus trabajos, siempre relacionados con la Historia, Arqueología, Historia del Arte, Didáctica de la Historia, etc.

PANTA REI is a digital journal focused on History and other sciences related to it. Its main objective is the transmission of scientific knowledge by giving also an opportunity to young researchers who want to make their way in the study of human and social sciences. It is composed by original studies related to History, as well as its didactics and promotion. The different sections of this journal are: research articles, interviews to professionals, recensions on monographs about current issues and reports about congresses or relevant scientific events.

All the articles published are subject to a revision process carried out by a minimum of two reviewers who are considered to be experts in the field of the article proposed. Our wish is to offer rigorous contents with quality and being of interest to the reader.

CEPOAT (Centre of Studies of the Middle East and Late Antiquity of the University of Murcia) is the institution in charge of the coordination and management of this journal. This is the centre from where the call for papers will be launched for all the people interested in publishing their papers, always related to History, Archeology, Art History, Teaching History, etc. 


\section{Normas de Publicación}

El autor se compromete a enviar trabajos originales, que no se encuentren publicados en otras revistas ni en otros idiomas. Así mismo, el mismo artículo no podrá ser presentado en otras revistas mientras dure el proceso de evaluación.

\section{Envío y presentación de originales}

Los artículos se enviarán exclusivamente a través del correo electrónico a la dirección pantarei@um.es. Los textos serán enviados en formato DOC y las imágenes en formato JPEG o TIFF, y con un tamaño mínimo de 2000 px. Éstas no aparecerán incorporadas en el texto, sino enviadas en archivo aparte y correctamente numeradas según su posición en el texto. Junto al trabajo, se rellenará y enviará un documento aparte en el que se especifiquen los datos del autor siguiendo el modelo disponible en la página Web de la revista.

Para la redacción de los trabajos se tendrá en cuenta el Manual de la American Psychological Association, en su sexta edición. La extensión máxima de los trabajos será de 30 páginas. La tipografía será Arial 11, con interlineado sencillo y sin espacio alguno entre párrafos. El texto deberá ir justificado a ambos márgenes y sin sangría en los primeros párrafos. Los márgenes serán de $2,50 \mathrm{~cm}$. En los casos en los que fuera necesario incorporar notas, éstas irán a pie de página, enumeradas consecutivamente, con tipografía Arial 10, interlineado sencillo y justificadas a ambos márgenes.

Una información más detallada se encuentra disponible en la página http://www.um.es/cepoat/ pantarei.

\section{Proceso de valoración y evaluación}

Una vez recibidos los trabajos, la Revista realizará una primera valoración. Si el trabajo enviado se ajusta a las normas de presentación propuestas, la temática es coincidente con la línea editorial de la revista y posee la calidad científica necesaria, será remitido al consejo asesor para una primera evaluación. Si no es así en este primer paso se puede rechazar directamente los documentos que incumplan claramente la línea editorial.

Será el Consejo Asesor quien indique a la revista la originalidad, relevancia, estructura, redacción, aparato bibliográfico, etc. del trabajo enviado y, para ello, se designará a dos revisores expertos externos que evaluarán cada uno de los trabajos, que pueden formar parte (o no) de este Consejo Asesor. La selección de los revisores se ajustará a la temática y características metodológicas del trabajo. El nombre y filiación de los autores serán eliminados del trabajo para su revisión, así como los revisores actuarán de manera anónima y confidencial.

Los revisores deberán rellenar un informe de evaluación que centrará su atención en aspectos tales como características formales, originalidad y novedad de los trabajos, relevancia de las propuestas y los resultados, calidad metodológica y validez científica.

Una vez terminado el proceso se decidirá la aceptación o no de los mismos y su publicación en el número que sea pertinente, así como las modificaciones susceptibles de ser realizadas para su final publicación. Dicha notificación se enviará únicamente por correo electrónico, en un plazo máximo de seis meses. 


\section{Publishing rules}

The author is committed to submit original papers not having been published in other reviews or in other languages. In this way, it is not allowed for the same paper to be presented in other reviews during the evaluation process.

\section{Submission and presentation of originals}

The articles will be exclusively submitted by email to pantarei@um.es. The texts will be submitted in DOC format and the images in JPEG or TIFF format, and with a minimum size of 2000 px. Images will not be integrated in the text but sent in another file and properly numbered according to their position in the text. Attached to the paper, a document will be filled out and sent where the author's data will be specified following the model available on the website.

The sixth edition of the Manual of the American Psychological Association will be taken into account for the writing of the papers. The length of the papers must not exceed 30 pages. Typography will be Arial 11 , with simple line spacing and no space between paragraphs. The text must be justified on both margins without indentation in the first paragraphs. Margins size will be $2.50 \mathrm{~cm}$. Where it could be necessary the incorporation of notes, they will be at the bottom of the page, consecutively numbered with typography Arial 10, simple line spacing and justified on both margins.

More detailed information is available on the website: http://www.um.es/cepoat/pantarei.

\section{Examination and assessment process}

The Journal will submit the papers to a first examination once received. If the paper follows the presentation guidelines, the subject agrees with the editorial line of this journal, and possess the scientific quality required, it will be sent to the advisory council for a first assessment. If not, the documents which clearly fail to complete the editorial line may be rejected straightaway in this first step.

The Advisory Council will indicate the originality, relevance, structure, writing, bibliography, etc. of the text to the journal; for this purpose, two outside experts will be designated to review the papers; these experts can be (or not) part of this Advisory Council. The selection of the experts will adjust to the subject and methodological characteristics of the paper. Name and affiliation of the author will be eliminated from the text for its review, in this way experts will act anonymously and confidentially.

The experts will fill out an assessment report which will focus on aspects such as formal characteristics, originality and novelty of the papers, relevance and results of the proposal, methodological quality and scientific validity.

Once the process is finished, the acceptance or not of the papers and its publication in the corresponding edition will be decided, as well as the modifications that may be done for its final publication. This notification will be sent by email within 6 months maximum. 


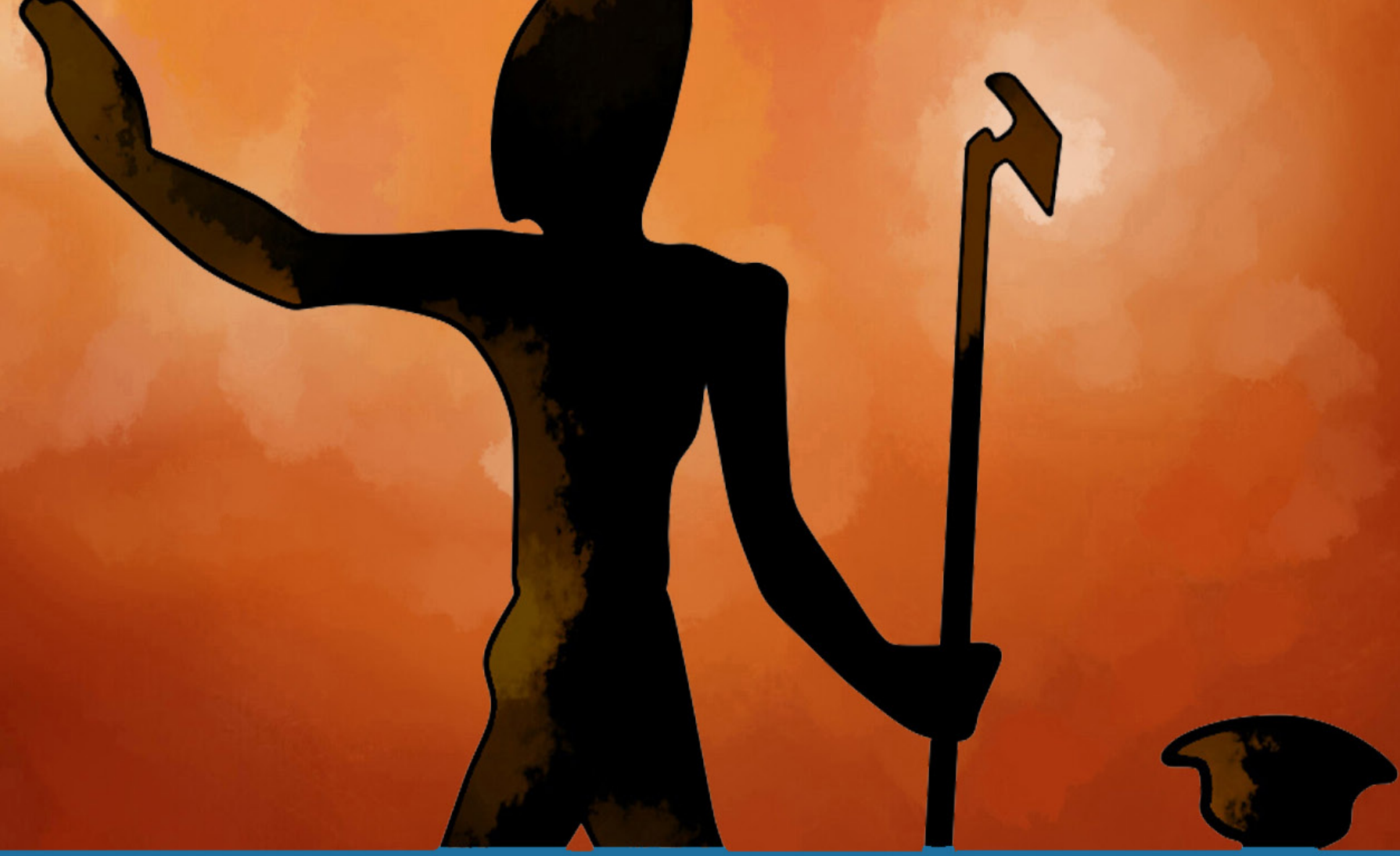

GepOA

centro de estudios de

próximo oriente y la

antigüedad tardía 